\title{
Reconstructing paleoclimate and paleoecology using fossil leaves
}

\author{
Daniel J. Peppe ${ }^{1}$, Aly Baumgartner ${ }^{1}$, Andrew Flynn ${ }^{1}$, Benjamin Blonder ${ }^{2}$ \\ ${ }^{1}$ Terrestrial Paleoclimatology Research Group, Department of Geosciences, Baylor University, \\ Waco, TX 76706, USA \\ ${ }^{2}$ Environmental Change Institute, School of Geography and the Environment, University of \\ Oxford, Oxford OX1 3QY, UK
}

\section{ABSTRACT}

Plants are strongly influenced by their surrounding environment, which makes them reliable indicators of climate and ecology. The relationship between climate, ecology, plant traits and the geographic distribution of plants based on their climatic tolerances have been used to develop plant-based proxies for reconstructing paleoclimate and paleoecology. These proxies are some of the most accurate and precise methods for reconstructing the climate and ecology of ancient terrestrial ecosystems and have been applied from the Cretaceous to the Quaternary. Despite their utility, the relationships between plant traits and climate that underlie these methods are confounded by other factors such as leaf life-span and phylogenetic history. Work focused on better understanding these confounding factors, incorporating the influence of phylogeny and leaf economic spectrum traits into proxies, expanding modern leaf trait-climate and ecology calibration datasets to additional biogeographic areas and climate regimes, and developing automated computer algorithms for measuring leaf traits are important growing research areas that will help considerably improve plant-based paleoclimate and paleoecological proxies.

Key words: paleobotany, leaf physiognomy, leaf margin analysis, leaf area analysis, CLAMP, digital leaf physiognomy, nearest living relative, leaf economic spectrum, leaf vein density, leaf mass per area

Suggested running header: Paleoclimate and paleoecology using fossil leaves 


\section{INTRODUCTION} photosynthesize and use water efficiently. Terrestrial plants use roots and rhizoids to take in water and minerals from the soil, which are essential for photosynthesis and for maintaining the water content of the plant. Leaves, a plant's primary photosynthetic organ, are used for gas and water exchange between the plant and the atmosphere, and generally have high surface to volume ratios. Plants must therefore balance water loss and uptake, light and carbon dioxide

40 fixation, and heat gain and loss from their environment as these affect their water use efficiency 41 and photosynthetic capacity. Thus for plants to be successful, they must have biochemical and

42 physiological adaptions that are well matched to the conditions they experience in their environment. Given these relationships between plants and their surrounding environment, a

44 plant's traits, such as the size and shape of its leaves, are intrinsically linked to the climate and 45 environment in which it is growing.

A variety of methods have been developed over the last 100 years using the

47 relationships between plant traits, climate, and ecology to develop paleoclimate and 48 paleoecological proxies that can applied to fossil leaves. In this review, we discuss univariate, 49 multivariate, and taxonomic methods for reconstructing paleoclimate and paleoecology using 50 fossil plants and their advantages and disadvantages. We also discuss new developments and

51 future research directions for leaf-based methods of reconstructing paleoclimate and 52 paleoecology. 
58 1915; Bailey and Sinnott, 1916). In particular, the sizes and shapes (physiognomy) of leaves

59 correlate strongly with temperature and moisture, and these relationships have been used to

60 develop proxies for reconstructing paleoclimate (e.g., Bailey and Sinnott, 1915; Bailey and

61 Sinnott, 1916; Webb, 1959, 1968; Wolfe, 1971; Dilcher, 1973; Wolfe, 1978;1979; Dolph and

62 Dilcher, 1980a, b; Greenwood, 1991; 1992; Wing and Greenwood, 1993; Wolfe, 1993, 1995;

63 Wilf, 1997; Wilf et al., 1998; Jacobs, 1999; Gregory-Wodzicki, 2000; Jacobs, 2002; Kowalski

64 and Dilcher, 2003; Greenwood et al., 2004; Traiser et al., 2005; Spicer, 2007; Adams et al.,

65 2008; Peppe et al., 2011; Teodoridis et al., 2011; Yang et al., 2011; Yang et al., 2015; Spicer,

66 2016). Additionally, the climatic tolerances of plants very strongly influence their geographic

67 distributions (e.g., Von Humbolt and Bonpland, 1807 Merriam, 1894; Küchler, 1964; Holdridge,

68 1967; Whittaker, 1975; Larcher and Winter, 1981;). Thus, a plant community, which is

69 comprised of species with overlapping geographic ranges and environmental tolerances, should

70 broadly reflect the climate in which it is growing, assuming the plant community is in equilibrium

71 with climate (e.g., Svenning and Sandel, 2013). The assumption that a plant community is in

72 equilibrium with climate is probably broadly true; however, there are notable situations when

73 plant communities can be out of equilibrium with climate, often referred to as disequilibrium or

74 community disequilibrium, particularly when climate is rapidly changing (e.g., Davis, 1986;

75 Svenning and Sandel, 2013; Blonder et al., 2015) The relationship between plant geographic

76 distributions and climate has been used to develop a variety of qualitative and quantitative

77 "nearest living relative" approaches, in which fossil taxa are systematically assigned to a closely

78 related modern plant taxon (i.e. their "nearest living relative") and then the fossil species

79 assemblage is matched to the climatic conditions of its "nearest living relatives" (e.g., Heer,

80 1870, 1878b, a, 1882; Chaney, 1938; Axelrod, 1948, 1952; MacGinitie, 1953; Axelrod and

81 Bailey, 1969; Hickey, 1977; Kershaw and Nix, 1988; Mosbrugger and Utescher, 1997).

82 Univariate and multivariate leaf physiognomic methods and nearest living relative

83 approaches have been applied hundreds, if not thousands, of times to Cretaceous and 
84 Cenozoic angiosperm-dominated fossils floras to reconstruct paleoclimate (as an example, see

85 supplement in Little et al. (2010) for a relatively complete list of papers from 1902 to 2010 that

86 have utilized univariate and multivariate leaf physiognomic methods). These climate

87 reconstructions are probably what fossil leaves are best known for among the broader

88 geological and paleoanthropological communities and there are a number of other excellent

89 detailed reviews on using angiosperm leaves to reconstruct climate (e.g., Chaloner and Creber,

90 1990; Greenwood, 2007; Wilf, 2008; Jordan, 2011; Royer, 2012a).

91 The basic observations underpinning leaf physiognomic paleoclimate methods are the

92 relationships between leaf teeth and mean annual temperature (MAT) and leaf size and mean

93 annual precipitation (MAP). In particular, the average leaf size of all species at a site positively

94 correlate with MAP and the percentage of woody, dicotyledonous (dicot) angiosperm species at

95 a site with toothed leaves and variables related to tooth count and size all negatively correlate

96 with MAT (Fig. 1, 2; e.g., Bailey and Sinnott, 1916; Webb, 1968; Dilcher, 1973; Wolfe, 1979;

97 Dolph and Dilcher, 1980a, b; Givnish, 1984; Greenwood, 1992; Wolfe, 1993; Wilf, 1997; Wilf et

98 al., 1998; Jacobs, 1999; Jacobs, 2002; Huff et al., 2003; Greenwood et al., 2004; Royer et al.,

99 2005; Peppe et al., 2011; Royer, 2012b; Yang et al., 2015). A number of studies have

100 demonstrated that leaf shape in at least some species of angiosperms changes in response to

101 climate both within the lifetime of a single plant (e.g., Royer et al., 2009b; Chitwood et al., 2016)

102 and over evolutionary time scales (e.g., Schmerler et al., 2012). Further, it appears that distinct

103 molecular pathways have evolved in plants to mediate changes in leaf shape in response to

104 changes in photosynthesis, temperature, and light quality (e.g., Chitwood and Sinha, 2016),

105 suggesting that plants have evolved mechanisms for changing leaf physiognomy in response to

106 climate and environment. 
Leaf size typically scales with local water availability (Fig. 2B; e.g., Webb, 1968; Givnish,

111 1984; Wilf et al., 1998; Jacobs, 1999; Malhado et al., 2009). Larger leaves tend to be warmer

112 because they have a thicker boundary layer (e.g., Vogel, 1970; Parkhurst and Loucks, 1972;

113 Gates, 1980; Givnish, 1984; Vogel, 2009). Photosynthetic and transpiration rates both increase

114 with increasing leaf temperature up to a maximum of $\sim 35-40{ }^{\circ} \mathrm{C}$, at which point plants begin to

115 experience heat stress and photosynthetic and transpiration rates rapidly decrease (e.g.,

116 Mooney et al., 1978; Salvuci and Crafts-Bandner, 2004; Wahid et al., 2007; Michaletz et al.,

117 2015). As a result, plants tend to plants tend to have smaller leaves in drier climates to reduce

118 evaporative cooling and larger leaves in wet climates where water loss related to increased

119 transpiration is less important, as a means of balancing heat loss via evaporative cooling and

120 water loss via transpiration (i.e., leaf energy balance) (e.g., Givnish, 1984; Montheith and

121 Unsworth, 2007). Smaller leaves usually have higher densities of major veins, which makes

122 them less vulnerable to embolisms caused by hydraulic disruptions that occur during drought

123 conditions (Scoffoni et al., 2011), which may also help explain why plants in dry climates have

124 smaller leaves than in wetter climates.

125 There are many hypotheses about the functional relationship between leaf teeth in

126 angiosperms and climate. Leaf teeth are sites of increased transpiration (Canny, 1990). Thus

127 in cold climates, teeth could be an adaptation for increased carbon uptake via enhanced sap

128 flow early in the growing season, which would allow rapid early season growth ("early season

129 gas-exchange hypothesis"; e.g., Billings, 1905; Bailey and Sinnott, 1916; Baker-Brosh and Peet,

130 1997; Wing et al., 2000; Royer and Wilf, 2006). Leaf teeth also commonly have hydathodes,

131 which are fixed pores in teeth that probably allow for water loss via guttation (Feild et al., 2005).

132 The hydathodes likely also help the plant enhance sap flow, which allows it to release excess

133 root pressure, preventing flooding of intercellular spaces in the leaf and, in colder climates,

134 freeze-thaw embolisms ("root-pressure hypothesis"; Feild et al., 2005). Leaf shape, and in

135 particular dissections of a leaf, are also probably related to bud packing ("bud-packing 
136 hypothesis"; Kodayashi et al., 1998; Couturier et al., 2011; 2012; Edwards et al. 2016).

137 Additionally, at least some plants exhibit seasonal heteroblasty, in which there are systematic

138 differences in leaf form associated with position along a branch ("seasonal heteroblasty

139 hypothesis"). More specifically, studies have shown that "preformed" leaves, which are leaves

140 that undergo a period of arrested development within a bud, differ in shape from "neoformed"

141 leaves, which are leaves that develop continuously within a bud (Critchfield 1960; 1971;

142 Edwards et al., 2016).

143 The early season gas-exchange hypothesis provides a functional explanation for the 144 relationship between leaf teeth and MAT because, based on this hypothesis, species with teeth 145 are able to grow and photosynthesize more rapidly early in the growing season than untoothed 146 species, which is a considerable advantage in colder climates with short growing seasons. The 147 root-pressure hypothesis (e.g., Feild et al., 2005) is not as clearly related to MAT because it is 148 related to water movement and freeze-thaw cycles through the plants, which has at best a weak 149 link to climate. However, this hypothesis might help provide a mechanism to explain how plants 150 maintain enhanced sap flow during rapid leaf expansion early in the growing season. The 151 relationship between leaf teeth, enhanced sap flow and increased water loss also helps explain 152 why toothed species are often more abundant in locally wet environments where the potential 153 negative implications of water loss through leaf teeth are mitigated (e.g., Wolfe, 1993; Burnham 154 et al., 2001; Kowalski and Dilcher, 2003; Greenwood, 2005; Royer et al., 2009a; Peppe et al., 155 2011). The seasonal heteroblasty hypothesis is also not directly linked to MAT. However, it 156 provides a functional explanation for how temperature may influence leaf development and may 157 help at least partially explain why leaf trait variability appears to be more strongly related to 158 annual climate instead of growing season climate. For example, in Viburnum, preformed leaves 159 tend to be rounder, more lobed and toothier than neoformed leaves, which were more elliptical 160 with greatly reduced teeth (Edwards et al., 2016). This seasonal variation in leaf shape could 161 due to two co-occurring forces: first, the different scenarios of early development (e.g., winter 
162 dormancy vs. continual development from bud primordia to leaf flush) and second, the plastic

163 response to different light and temperature regimes experienced in the early versus late season

164 (Edwards et al., 2016). The bud-packing hypothesis is based on the premise that there are

165 constraints on leaf shape that are driven by how the fold and boundaries of leaf primordial are

166 arranged in a bud, which is unlikely to be driven by climate. However, the bud-packing and

167 seasonal heterblasty hypothesis are very similar in that both argue that climate influences leaf

168 development within the bud, which in turn influences leaf shape, suggesting that climate plays

169 an important role in influencing leaf shape from the beginning of bud deel. Although each of

170 these hypotheses help explains some aspects of the relationship between leaf physiognomy

171 and climate, we still lack a physiological or evolutionary mechanism that fully explains how and

172 why the empirical relationships that have been observed between leaf physiognomy and climate

173 in modern floras exists. Work to better understand the mechanism linking climate and leaf

174 physiognomy is ongoing (see for example review in Chitwood and Sinha, 2016) and help offer

175 insights that will likely significantly improve leaf physiognomy-climate models in the future.

176 The occurrence of leaf teeth are likely also influenced by a variety of factors not directly

177 related to climate, such as phylogeny, leaf life-span, and leaf thickness. Phylogenetic history

178 influences the occurrence of leaf teeth (e.g., Little et al., 2010; Burnham and Tonkovich, 2011;

179 Hinojosa et al., 2011). This suggests that the leaf teeth-climate relationship observed in modern

180 floras may reflect a combination of plants' responses on both short term (i.e., seasonal) and

181 long term (i.e., evolutionary) time scales and processes of plant community assembly

182 (Schmerler et al., 2012). Plant leaf life-span and leaf thickness also influence the occurrence of

183 leaf teeth as both deciduous species and species with thinner leaves more commonly have

184 teeth than evergreen species and species with thicker leaves (Royer et al., 2012). However,

185 neither plant life-span (i.e., deciduous vs. evergreen) nor leaf thickness correlate strongly with

186 MAT (e.g., Reich et al., 1999; Wright et al., 2004; Wright et al., 2005; Royer et al., 2012),

187 indicating that non-climatic factors also play a role in the occurrence of leaf teeth. The influence 
188 of phylogeny, leaf life-span, leaf thickness and other non-climatic factors on leaf physiognomic 189 methods for reconstructing climate is unclear, but may inherently bias paleoclimate estimates

190 (see Royer, 2012a for more details). Leaf physiognomic methods that incorporate phylogenetic 191 and leaf ecological information are in development and aim to address the potential influence of 192 phylogeny and other non-climatic drivers of leaf teeth on paleoclimate estimates.

PLACE FIGURE 2 ABOUT HERE; WIDTH = 2 COLUMNS

\section{Methods of paleoclimate reconstruction}

197 Methods that reconstruct paleoclimate using fossil leaves can be broadly divided into two main

198 types: leaf physiognomic methods and nearest living relative (NLR) methods. Leaf

199 physiognomic methods use the relationship between leaf traits and climate, while NLR

200 approaches use the climatic, and less commonly, the ecological requirements of the taxon that 201 is the nearest living relative to the fossil taxon being studied.

Leaf physiognomic methods - univariate approaches: The relationship between leaf

204 physiognomy and climate was first noted a century ago by Bailey and Sinnott $(1915 ; 1916)$ and

205 this relationship has become the cornerstone of leaf physiognomic paleoclimate methods (e.g., 206 Wolfe, 1971, 1979; Dilcher, 1973; Wing and Greenwood, 1993; Wolfe, 1993; Wilf, 1997; Wilf et 207 al., 1998; Jacobs, 1999; Gregory-Wodzicki, 2000; Greenwood et al., 2004; Spicer, 2007; Peppe 208 et al., 2011; Spicer, 2016). In particular, Bailey and Sinnott $(1915 ; 1916)$ noted that the 209 proportion of a flora with entire-margined leaves and with large leaves increased with 210 decreasing latitude and suggested that these relationships could be used to estimate ancient 211 climate. Following this pioneering work, paleobotanists used similarities between the relative 212 abundance of species with entire margins and the different size classes of leaves in modern 213 vegetation, as well as Paleogene and Neogene floras to qualitatively infer paleoclimate (e.g., 
214 MacGinitie, 1953; Wolfe and Hopkins, 1967; Hickey, 1977; Christophel and Blackburn, 1978).

215 Despite the acknowledgement of the relationship between leaf physiognomy and climate and its 216 application to fossil floras and ancient climates, it took more than a half a century before the 217 qualitative relationships noted by Bailey and Sinnott $(1915 ; 1916)$ were demonstrated 218 quantitatively.

219 Using floral lists from East Asia, Wolfe (1979) demonstrated a remarkably strong 220 relationship between the percentage of woody dicot species at a site with entire margins, 221 defined as species lacking either marginal teeth or lobes, and MAT. However, although Wolfe 222 (1979) presented a linear regression in his figure that showed the relationship between the 223 percent of species with entire margins and MAT, the statistics and the equation for the 224 regression were not presented. This relationship was then quantified by Wing and Greenwood 225 (1993) using linear regression to develop a predictive equation to estimate MAT based on the percentage of woody dicot species at a site with entire margined species:

where LMAT is mean annual temperature estimated using leaf margin analysis and $P$ is defined as:

$$
\text { (Eq. 2) } P=\frac{r}{n}
$$

231 where $n$ is the total number of species sampled, $r$ is the number of species at a site with entire 232 margins, and $(n-r)$ is the number of species with toothed margins. In cases where a species 233 has both entire and non-entire margins, the $r$ score for the species is 0.5 . 234 Since Wing and Greenwood's (1993) recalculation of Wolfe's (1979) East Asian leaf 235 margin analysis (LMA) regression, the relationship between leaf margin and MAT has been 236 tested on floras from most major geographic locations and climate biomes on earth and many 237 global, regional, and site specific LMA regressions have been developed (Fig. 1; Table 1). 238 Significantly, since Wilf (1997), leaf margin type has been classified as toothed or entire (i.e., 
non-toothed). Although many factors confound the relationship between margin percentage and

240 MAT, as discussed above and reviewed by others (e.g., Greenwood, 2007; Jordan, 2011;

241 Peppe et al., 2011; Royer, 2012a; Royer et al., 2012), the relationship between leaf margin and

242 MAT is typically statistically significant and similar across geographic regions (Fig. 2a). Based

243 on these LMA regressions, LMA has been applied to numerous of Cretaceous and Cenozoic

244 fossil floras to estimate MAT using fossil leaves (see for example studies cited in supplementary

245 materials in Little et al., 2010).

\section{PLACE TABLE 1 ABOUT HERE}

The accuracy and precision of MAT estimates using LMA has been shown to improve when more species are sampled. In his original LMA work, Wolfe (1971) suggested $\geq 30$ species were necessary to calculate a reliable MAT estimate, though he suggested that the minimum bar was $\geq 20$ species, which has been the practice of most paleobotanists. While the total number of species sampled is important, the proportional recovery of the total flora is more 254 significant. For example, Burnham et al. $(2001 ; 2005)$ found that in very diverse, extant floras 255 with 55 to $>400$ species, $\geq 25$ of the most common species had to be sampled to make an 256 accurate MAT estimate using LMA. This suggests that LMA should only be applied to well257 sampled floras and that MAT estimates made using poorly sampled floras and/or floras with low 258 species richness are unlikely to be accurate.

Sample size also affects the uncertainty of LMA estimates. Based on their reanalysis of 260 the Wolfe (1979) East Asian LMA, Wing and Greenwood (1993) calculated the standard error of 261 LMA estimates of MAT to be $\pm 0.8^{\circ} \mathrm{C}$. However, the standard errors of the East Asian LMA 262 regression alone considerably underestimate the uncertainty of leaf margin analysis mean 263 annual temperature (LMAT) estimates. To account for additional uncertainty in LMAT 264 estimates, Wilf (1997) proposed using the binomial sampling error for LMA estimates, which 
265

266

267

268

269

270

271

272

273

274

275

276

277

278

279

280

281

282

283

284

285

286

287

288

289

accounts for the standard error of the LMA regression and uncertainty related to sampling the species richness of a fossil flora:

(Eq. 3) $\sigma[$ LMAT $]=c \sqrt{ } \frac{\mathrm{P}(1-\mathrm{P})}{n}$

where $c$ is the slope of the MAT vs. leaf-margin regression in the dataset used, $P$ is the proportion of species with entire margins, and $n$ is the number of species sampled.

Wilf (1997) suggested the minimum uncertainty of a LMAT estimate was at least \pm 2.0

${ }^{\circ} \mathrm{C}$ and that the larger of the two errors given by the binomial sampling error and the standard error of the regression if it were $>2.0^{\circ} \mathrm{C}$ was the appropriate uncertainty for LMAT estimates. In Wilf's (1997) study, he noted that the binomial sampling error only accounted for part of the total uncertainty in LMAT estimates. Miller et al. (2006) incorporated the uncertainties associated with the estimation of the proportion of species at a site with teeth $(P)$ into the estimation of uncertainty of LMAT estimates:

$$
\text { (Eq. 4) } \sigma[\text { LMAT }]=\mathrm{c} \sqrt{[}\left[\left(1+\varphi(n-1)(P(1-P)) \frac{\mathrm{P}(1-\mathrm{P})}{n}\right]\right.
$$

where $c$ is the slope of the MAT vs. leaf-margin regression in the dataset used, $P$ is the proportion of species with entire margins, $n$ is the number of species sampled and $\varphi$ is the overdispersion factor for $P$, which was calculated by Miller et al. (2006) to be 0.052 .

The Miller et al. (2006) estimation of uncertainty provides the best measurement of the precision of LMAT; however, they noted that there may be additional systematic uncertainties in LMAT based on sampling differing forested environments. Greenwood et al. (2004) documented this effect in a series of sites from Australia that showed a significant correlation between margin percentage ant MAT $(r 2=0.57, P<0.001)$, but a larger uncertainty than datasets from East Asia and North and Central America $\left(\sigma= \pm 3^{\circ} \mathrm{C}\right)$. Based on a large global compilation of sites, Peppe et al. (2011) showed that the uncertainty associated with LMAT estimates using a globally derived LMA is at least $\pm 4^{\circ} \mathrm{C}$. Conservatively, given uncertainties associated with sampling (accounted for in equation 4) and all of the potential confounding 
290 factors that affect the relationship between climate and the proportion of species with teeth 291 uncertainties, which are currently not accounted for in any uncertainty calculation, a minimum 292 uncertainties for LMAT estimates is probably $\pm 5^{\circ} \mathrm{C}$ (see also Jordan, 1997, 2011; Royer, 293 2012a). Despite these uncertainties, LMAT estimates are typically in agreement with other 294 proxies and are generally accurate, and reasonably precise, making the LMA method a useful 295 tool for estimating MAT in the past.

$296 \quad$ Building on another of Bailey and Sinnott's $(1915 ; 1916)$ observations that large leaves 297 were more common in warm, mesic environments, several researchers have noted a strong 298 positive relationship between leaf size and mean annual precipitation (MAP) (Webb, 1968; 299 Dilcher, 1973; Dolph and Dilcher, 1980a, b; Hall and Swaine, 1981; Givnish, 1984). The 300 correlation between leaf size and MAP was first quantified by Givnish (1984) for floras from 301 South America, Central American and Australia. Wilf et al. (1998) expanded on Givnish's 302 (1984) work and used the correlation between the mean of the natural log of species' leaf area 303 (MInA) and the natural log of MAP (InMAP) at 50 sites from North America, Central America, 304 South America, and Africa to develop a predictive equation for MAP:$$
\text { (Eq. 5) } \ln (\mathrm{MAP})=0.548 \mathrm{MlnA}+0.768
$$

MlnA was calculated for the entire flora by first determining the Raunkier-Webb (Webb, 1959) size category for each species and then determining the proportion of species in each of the 308 seven size categories:

$$
\text { (Eq. 6) } \mathrm{MlnA}=\sum a_{i} p_{i}
$$

310 Where $a_{i}$ is the seven means of the natural log areas of the size categories and $p_{i}$ is the 311 proportion of species in each size category. This method of estimating MAP using leaf area is 312 known as leaf area analysis (LAA; Table 1). The standard error for In(MAP) for LAA is 0.359 313 (Wilf et al., 1998).

314 Following the work of Wilf et al. (1998), the relationship between leaf area and MAP has 315 been tested on a series of floras from Bolivia and predominately Northern Hemisphere 
316 temperate regions (Gregory-Wodzicki, 2000), floras from equatorial Africa (Jacobs, 1999; 2002), 317 and floras from North America, Central America, South America, Asia, and Oceania (Peppe et 318 al., 2011) (Fig. 2). These correlations have been used to develop several additional LAA 319 equations to estimate MAP (Table 1, Fig. 2; Jacobs, 1999; Gregory-Wodzicki, 2000; Jacobs, 320 2002; Peppe et al., 2011). Using a dataset of sites from equatorial Africa and Bolivia, Jacobs 321 and Herendeen (2004) also documented a significant relationship between leaf area and 322 precipitation during the three wettest months, which they used to develop a proxy for wet month 323 precipitation (Table 1).

Although the relationship between leaf area and mean annual precipitation is significant, 325 LAA estimates of MAP are not accurate and the uncertainties are relatively large. Peppe et al. 326 (2011) used a jackknife-type approach for a dataset of 92 globally distributed sites to gauge the 327 accuracy of LAA, and found that LAA tended to underestimate MAP at sites with relatively high 328 precipitation and overestimate MAP at sites with relatively low precipitation. These results and 329 the original work of Wilf et al. (1998) suggest that LAA is not a precise estimator of MAP and 330 instead is primarily a useful tool for roughly estimating MAP.

331 Leaf size is also influenced by a variety of other factors including temperature, elevation, 332 soil fertility, and leaf life-span (e.g., Webb, 1968; Dolph and Dilcher, 1980a, b; Givnish, 1984; 333 Wolfe, 1995; Halloy and Mark, 1996; McDonald et al., 2003; Peppe et al., 2011) confounding 334 the relationship between MAP and leaf size leading to the low accuracy and precision of MAP 335 estimates made using LAA. Additionally, available water appears to be the main control on leaf 336 size (Givnish, 1984). In addition to precipitation, plant available water is influenced by many 337 factors such as rates of evapotranspiration, temperature, seasonality, the position of the water 338 table, and hydrologic conductance within the soil. As a result, MAP may not be a good proxy for 339 available water in many situations, which perhaps explains the relatively poor accuracy and 340 precision of LAA. 
Although LMA, and to a lesser extent LAA, have been widely adopted by the

342 paleobotanical community and the fossil leaf based MAT and MAP estimates made using the

343 methods are often considered some of the most robust estimates for terrestrial paleoclimates,

344 both methods rely on single characters. Leaf size and shape is remarkable diverse and many

345 aspects of leaf physiognomy vary with climate (e.g., Wolfe, 1993, 1995; Royer et al., 2008;

346 Royer et al., 2009b; Schmerler et al., 2012). Additionally, in at least some cases, multiple leaf

347 physiognomic traits appear to co-vary with climate variables (Dolph and Dilcher, 1980a, b;

348 Peppe et al., 2011). Further, although LMA and LAA commonly agree with other climate proxy

349 reconstructions, in many cases, these proxies provide cooler and drier estimates of MAT and

350 MAP than other proxies (e.g., Liang et al., 2003; Fricke and Wing, 2004; Wing et al., 2009;

351 Adams et al., 2011). Because LMA and LAA are univariate approaches, the incorporation of

352 additional leaf characters may lead to improvements in paleoclimate estimates.

Leaf physiognomic methods - multivariate approaches: In an attempt to improve on character scores and climate data from a modern training set are analyzed using canonical correspondence analysis (CCA; Wolfe, 1995; Kovach and Spicer, 1996). The resultant eigenvectors for the climate and leaf physiognomic variables are projected onto the major axes

361 of variation, which roughly correlate with temperature (first axis) and moisture (second axis)

362 (Wolfe, 1995). A second-order polynomial fit for a climate variable to the eigenvector is then 363 used to develop a predictive equation for that climate variable, which can then be applied to a 364 fossil flora (Wolfe, 1995). In practical terms, this means that the leaf character scores of a fossil 365 flora are projected onto each of the climate variable vectors in the CLAMP calibration dataset 366 and those scores are used to estimate each climate variable. CLAMP estimates MAT, warm 
month mean temperature, cold month mean temperatures, growing season length, growing season precipitation, mean monthly growing season precipitation, precipitation in the three wettest and three driest months, relative humidity, specific humidity, and enthalpy (Wolfe, 1995;

370 Spicer, 2016). The standard errors for CLAMP climate estimates are small (Wolfe, 1993, 1995;

371 Spicer et al., 2005); however, the errors are only based on the analytical uncertainty of CCA and

372 do not account for any additional uncertainties related to the leaf character states, character

373 scoring, precision in the climate variables of the calibration data set, or factors that potentially

374 confound leaf character-climate relationships. Thus, the standard errors reported for CLAMP

375 considerably underestimate uncertainty and are artificially precise. For example, at minimum,

376 the uncertainties in MAT estimates made using CLAMP are similar to, if not larger than those for 377 leaf margin analysis (see Figure 1 in Royer, 2012a).

378 CLAMP was originally calibrated with 106 sites with a limited global coverage, and since 379 has been expanded to two primary calibration datasets primarily derived from floras from the 380 Northern Hemisphere: (1) PHYSG3BR, which includes 144 temperature Northern Hemisphere 381 sites, and (2) PHYSG3AR, which includes 173 Northern Hemisphere sites that include sites that 382 experience very cold winter temperatures (e.g., Wolfe, 1993, 1995; Wolfe and Spicer, 1999; 383 Spicer et al., 2004; Spicer, 2016). Since then Spicer and colleagues (see Spicer, 2007, 2016) 384 have assessed regional differences in the relationship between climate and CLAMP characters 385 in South America (Gregory-Wodzicki, 2000; Kowalski, 2002), South Africa (Steart et al., 2011), 386 New Zealand and Australia (Kennedy et al., 2002; Kennedy et al., 2014) and expanded the 387 calibration datasets to include floras in regions that experience a monsoon climate (Jacques et 388 al., 2011; Khan et al., 2014), floras from the Southern Hemisphere (Kennedy et al., 2014), and 389 floras from temperate and high latitudes in the Northern and Southern Hemispheres (Yang et 390 al., 2015). The CLAMP modern calibration originally used climate data from local climate 391 stations (Wolfe, 1993, 1995), but more recent studies follow Spicer et al. (2009) and use climate 392 data extracted from the New et al. (2002) global, gridded climate model. CLAMP analyses were 
393 originally performed using a series of spreadsheets and conducting a CCA using the software 394 package CANACO 4.5 (Microcomputer Power, Ithaca, NY, USA). CLAMP analyses can now be 395 performed online (Yang et al., 2011) through the CLAMP website:

\section{6 http://clamp.ibcas.ac.cn/CLAMP Run Analysis.html.}

Although CLAMP has been widely applied (reviewed in Spicer, 2007, 2016), the method

398 has several shortcomings that have been reviewed many times (e.g., Jordan, 1997; Wilf, 1997;

399 Wiemann et al., 1998; Wilf et al., 1998; Green, 2006; Peppe et al., 2010; Jordan, 2011). The

400 most notable criticisms are that (1) based on the character distributions, CCA may not be the

401 most appropriate technique for predicting climate (Green, 2006; Peppe et al., 2010), (2) at least

402 some of the leaves in the original calibration dataset were scored incorrectly (Peppe et al.,

403 2010), (3) many of the CLAMP character states are at least partially ambiguous and the original

404 scoring procedures were poorly defined (Wilf, 1997; Wiemann et al., 1998; Wilf et al., 1998,

405 1999; Green, 2006), (4) the CLAMP characters are discrete and categorical despite the fact that

406 leaf traits are continuous (i.e., number of teeth, leaf size) and many of the continuous traits

407 correlate strongly with temperature and/or precipitation (Huff et al., 2003; Royer et al., 2005;

408 Royer et al., 2008; Peppe et al., 2011), and (5) some CLAMP character states only correlate 409 weakly to climate and/or have no physiological explanations for climate causality.

410 One of the underlying assumptions of CCA is that the variables are unimodally

411 distributed (ter Braak, 1986). However, Green (2006) and Peppe et al. (2010) showed that

412 many of the CLAMP leaf character distributions were not unimodally distributed. Following this

413 work, Teodoridis et al. (2011) developed transformations of the CLAMP PHYSG3BR and

414 PHYSG3AR calibration datasets that could be used as "correction coefficients" to account for

415 the non-normality of the CLAMP leaf character state data.

$416 \quad$ Peppe et al. (2010) rescored a subset of Wolfe's $(1993,1995)$ original calibration sites

417 and demonstrated that the site-mean leaf area of 38 sites in the CLAMP calibration and the leaf 418 area scores of the species in each site were considerably underestimated relative to digitally 
measured leaf area. When the influence of this underestimation of leaf area was accounted for,

420 it added a considerable amount of uncertainty to all CLAMP climate estimates (Peppe et al.,

421 2010). Spicer and Yang (2010) assessed the influence of leaf size on MAT and enthalpy

422 estimates made using CLAMP and found that when the leaf size character state was removed it

423 increased uncertainty, but caused only relatively small changes in MAT and enthalpy. This

424 result indicates that leaf size contributes relatively little information when predicting at least

425 some climate variables with CLAMP and suggests that some climate predictions could be

426 improved by changing the leaf character states used in CLAMP. Spicer and Yang (2010) only

427 indirectly addressed the main criticism of Peppe et al. (2010), that the leaf area scores in the

428 CLAMP calibration dataset are underestimated, by suggesting that the measured leaf area bias

429 was the result of measuring leaf area directly rather than using the CLAMP leaf area template.

430 This is an important distinction because it means that when performing a CLAMP analysis, leaf

431 area can only be scored using the CLAMP leaf area template and if leaf area is measured

432 directly, even if it is more accurate, it will add considerable uncertainty to the CLAMP estimates.

433 Several studies have documented issues with the ambiguity of CLAMP character states

434 and original scoring procedures (Wilf, 1997; Wiemann et al., 1998; Wilf et al., 1998, 1999;

435 Green, 2006; Peppe et al., 2010). Recently, Spicer (2016) updated the character state 436 definitions and scoring protocol in an attempt to eliminate the ambiguities. To test these

437 revisions, Spicer and Yang (2010) had students collect and score leaves from a forest reserve

438 near Beijing, China and found that the resulting CLAMP climate estimates were different, though

439 reasonably similar, suggesting the revised CLAMP scoring protocol and character definitions

440 have helped eliminated some of the problems with the original method.

441 Although there has been recent work to expand the CLAMP calibration datasets to a

442 wider range of biogeographic regions and climate regimes (e.g., Jacques et al., 2011; Kennedy

443 et al., 2014; Yang et al., 2015), the inherent issues with using categorical variables and leaf

444 characters that are not physiologically linked to climate have not been addressed. Furthermore, 
445 many studies have demonstrated that climate estimates made using CLAMP are similar to, or

446 less accurate than, estimates made using LMA and LAA (e.g., Wilf, 1997; Wiemann et al., 1998;

447 Gregory-Wodzicki, 2000; Kowalski, 2002; Kowalski and Dilcher, 2003; Hinojosa et al., 2006a;

448 Hinojosa et al., 2006b; Dilcher et al., 2009; Royer, 2012a; Smith et al., 2012; West et al., 2015).

449 Rather than apply CCA, several researchers have used the CLAMP calibration datasets

450 or comparable datasets using the CLAMP characters to develop multiple linear regressions

451 models for paleoclimate (e.g., Wing and Greenwood, 1993; Gregory, 1994; Gregory and

452 Mclntosh, 1996; Jacobs and Deino, 1996; Stranks and England, 1997; Wiemann et al., 1998;

453 Gregory-Wodzicki, 2000; Kowalski and Dilcher, 2003; Lielke et al., 2012). However, these

454 methods have not been widely adopted. Further, because they utilize the CLAMP calibration

455 dataset and leaf character states, they suffer from many of the same problems as CLAMP.

456 Given the potential problems with CLAMP, and in particular the subjectivity of scoring

457 leaf traits, Huff et al. (2003) proposed digital leaf physiognomy (DiLP), which is a method for

458 measuring leaf traits digitally. The benefits of DiLP are that it increases the reproducibility of

459 leaf character scores and that it measures continuous variables, such as number of teeth and

460 tooth size, that have functional or physiological links to climate. In their preliminary study of

461 three floras, Huff et al. (2003) found that continuous variables related to tooth number and tooth

462 shape varied between floras and with temperature, demonstrating that the incorporation of

463 continuous variables had the potential to improve fossil leaf based paleoclimate models. A

464 subsequent study by Royer et al. (2005) showed that leaves in cold climates are more highly

465 dissected and have more, larger teeth. Using data from 17 sites from the east coast of the

466 United States and Panama, Royer et al. (2005) developed a preliminary multiple linear

467 regression model for predicting MAT that was more accurate and precise than LMA and

468 CLAMP. However, the study was based on sites from a relatively limited range in biogeography

469 and precipitation. Peppe et al. (2011) quantified DiLP leaf physiognomic variables and climate

470 using 92 globally distributed and climatically diverse sites and noted the same patterns between 
471 leaf traits and MAT as observed by Huff et al. (2003) and Royer et al. (2005) and also that

472 leaves in wet climates were larger and had fewer, smaller teeth. Using these relationships,

473 Peppe et al. (2011) developed multiple linear regression models for MAT and MAP (Table 1):

(Eq. 7) $\mathrm{MAT}=0.210(E)+42.296(F D R)+2.609(T: I P)-16.004$

(Eq. 8) $\ln (\mathrm{MAP})=0.298 \ln (A)-2.71 \ln (P R)+0.279 \ln (T: I P)+3.033$

476 where $E$ is the proportion of species at the site with entire margins, $F D R$ is feret's diameter ratio

477 (Diameter of a circle with the same area as the blade area $(\mathrm{cm}) /$ longest measurable line across

478 blade area $(\mathrm{cm})$ ), $T: I P$ is the number of teeth to internal perimeter (number of teeth/perimeter of

479 the leaf after teeth are removed $(\mathrm{cm})$ ), $A$ is leaf area, and $P R$ is perimeter ratio (perimeter of the 480 leaf blade/internal perimeter $(\mathrm{cm}) /$ perimeter of the leaf after teeth are removed $(\mathrm{cm}))$. The leaf 481 character states used in these models are defined in Peppe et al. (2011). The standard error for 482 the MAT model is $\pm 4.0^{\circ} \mathrm{C}$ and for the MAP model is 0.60 .

DiLP estimates of MAT and MAP are significantly more accurate than MAT estimates made using LMA and marginally better than MAP estimates using LAA (Peppe et al., 2011).

DiLP MAT estimates made for several fossil floras are also in better agreement with other proxy reconstructions of MAT than LMAT estimates (Peppe et al., 2011). This suggests that the DiLP method potentially offers improvements over other existing leaf physiognomic methods. DiLP 488 also offers three additional advantages over CLAMP, LMA, and LAA: (1) it minimizes ambiguity 489 in leaf character scoring because computer algorithms process most of the measurements; (2) 490 the DiLP models use mostly continuous variables, such as feret's diameter ratio and number of 491 teeth:internal perimeter; and (3) the leaf characters used in the DiLP models have a functional 492 connection to climate and include traits that display phenotypic plasticity between growing 493 seasons (Royer et al., 2009b) indicating the traits can respond quickly to climate change. 494 Despite its advantages, a major limitation of DiLP is that some of the characters used in 495 the DiLP MAT and MAP models (feret's diameter ratio and leaf area) require relatively complete 496 preservation of leaves. Unfortunately, fossil leaves are typically fragmented (e.g., Greenwood, 
497 1992, 2005, 2007; Spicer et al., 2005), which means that it may not be possible to score all

498 DiLP characters for all fossil taxa. In an sensitivity experiment using modern leaves, Royer et 499 al. (2005) tested the effect of fragmentary leaves on LMA and DiLP and found that in all cases 500 fragmentary leaves led to less precise climate estimates, but when leaves were $50 \%$ intact, 501 LMA estimates of MAT had larger errors than estimates made with DiLP. Additionally, Royer et 502 al. (2005) found that while multiple specimens should be scored when possible, only one 503 specimen per species needed to be digitally score to provide an accurate MAT estimate using

504 DiLP. These results suggest that although there is some information lost when leaves are 505 fragmentary, DiLP may still able to provide reasonable estimates of paleoclimate when 506 fragmentary leaves are scored. In an attempt to address the fact that fossil leaves are 507 commonly incomplete, Peppe et al. (2011) developed a detailed protocol for processing 508 incomplete leaves. In practice DiLP characters can be scored in most fragmentary leaves, 509 provided that at least $25 \%$ of the leaf is preserved and the fragment preserves both the margin 510 and the mid-vein. Additionally, recent work documented a strong relationship between leaf vein 511 density and leaf size (e.g. Sack et al., 2012), and was used to develop a "vein scaling" transfer 512 function for estimating leaf area from fragmentary fossils (Merhofer et al., 2015). The 513 incorporation of leaf area estimates made using vein scaling also has the potential to increase 514 the number of fragmentary fossil specimens that can be used to reconstruct MAT and MAP. 515 DiLP has been successfully applied to several fossil floras (Peppe et al., 2011; Flynn et 516 al. 2016), which suggests that the method has great potential to be more widely applied.

517 However, there are some examples in which the climate estimates made using DiLP were 518 unreasonable based on other lines of evidence (Peppe et al., 2011). For example, estimates for 519 the Laguna del Hunco flora from Argentina, were cooler and drier than expected (Peppe et al., 520 2011), based on the habitat preference of some of the species present in the flora (Wilf et al., 521 2009). This discrepancy may be because the physiognomic-climate space of South America is 522 not fully characterized in the current DiLP calibration. 
524 recommend using CCA as an initial check to confirm that a fossil floras physiognomic space is

525 captured by the calibration data. Peppe et al. (2001) and Peppe (unpublished data) have

526 analyzed two floras that plotted outside the calibrated physiognomic space: Bonanza, an

527 Eocene flora from North America, and Rusinga R3, a Miocene flora from Kenya (Fig. 3). Peppe

528 et al. (2011) argued that the Bonanza flora was likely on outlier because the fossil flora was a

529 mixture of two habitats resulting in a unique site mean physiognomic space. There are no

530 modern floras from Africa in the current DiLP calibration, and thus the Rusinga R3 flora from

531 Kenya likely samples a currently uncalibrated physiognomic space (Fig. 3). Future work

532 expanding the calibration dataset to more sites from the Southern Hemisphere, and particularly

533 from Africa, may help improve DiLP so that the method can be applied to a wider range of

534 floras. reasonably accurate and precise estimates, they are not without their inherent disadvantages.

541 There are a variety of factors that affect and confound the relationships between leaf

542 physiognomy and climate. In this review, we will briefly discuss three of the important factors

543 that limit leaf physiognomic methods: life history, phylogeny, and plant ecology. For a review of

544 some of the other confounding factors, such as taphonomy, local water availability, position in

545 the canopy, soil fertility, and nutrient availability, see the recent reviews by Greenwood (2007),

546 Jordan (2011), and Royer (2012).

547 The original leaf margin analysis calibration data and most subsequent calibrations, as

548 well as most of the calibration data that underlies CLAMP and DiLP, are primarily derived from 
549 Northern Hemisphere temperate floras (e.g., Wolfe, 1979; Wolfe, 1993, 1995; Wilf, 1997;

550 Kowalski and Dilcher, 2003; Su et al., 2010; Peppe et al., 2011). However, the relationship

551 between leaf physiognomy and climate, and particularly between the presence of leaf teeth and

552 MAT, is distinctly different in the Southern Hemisphere where floras typically have a higher

553 percentage of untoothed species than their Northern Hemisphere counterparts (e.g., Wolfe,

554 1979; Upchurch and Wolfe, 1987; Gregory-Wodzicki, 2000; Kowalski, 2002; Greenwood et al.,

555 2004; Hinojosa et al., 2006a; Aizen and Ezcurra, 2008; Hinojosa et al., 2011; Steart et al., 2011;

556 Kennedy et al., 2014). Further, in Africa, Australia, and New Zealand the correlation between

557 leaf size and MAT is as strong, if not stronger, than between leaf margin and MAT (Webb, 1968;

558 Greenwood, 1992, 1994; Jacobs, 1999; Jacobs, 2002).

559 These hemispheric differences could be due to regional differences in environment, such

560 as thermal seasonality or soil fertility, phylogenetic differences, leaf life-span (i.e., lack of

561 temperate deciduous forests in the Southern Hemisphere), or differences in plant ecology (e.g.,

562 Upchurch and Wolfe, 1987; Wolfe and Upchurch, 1987; Jordan, 1997; Greenwood et al., 2004;

563 Jordan, 2011; Peppe et al., 2011). Researchers have also found that there are considerable

564 differences between physiognomy and climate when comparing the CLAMP PHYSG3BR and

565 PHYSG3AR to regional floras in South America, Australia, and New Zealand (e.g., Gregory-

566 Wodzicki, 2000; Kennedy et al., 2002; Kowalski, 2002; Hinojosa et al., 2006a; Steart et al.,

567 2011; Kennedy et al., 2014). There are also notable differences in the relationship between leaf

568 physiognomy and climate in some of the DiLP characters (e.g., number of teeth vs. temperature

569 and leaf area vs. temperature) between sites from the different hemisphere, and particularly

570 from Australia and New Zealand (Peppe et al., 2011). Finally, although much research has

571 focused on the regional differences in the relationships between climate and physiognomy, most

572 of the regional datasets have not been added to the larger calibration dataset or used to

573 develop new models (e.g., Steart et al., 2011 from South Africa). As a result, most LMA

574 regressions and the most commonly used CLAMP calibration datasets PHYSG3BR and 
575 PHYSG3AR have few to no floras from Africa, South America, and Oceania. The net effect is

576 the most leaf physiognomic models do a relatively poor job reconstructing the paleoclimate of

577 Southern Hemisphere floras (Kowalski, 2002; Greenwood et al., 2004; Hinojosa et al., 2006a;

578 Peppe et al., 2011).

579 Two of the hypothesized explanations for the differences between Northern and

580 Southern Hemisphere floras, phylogeny and plant ecology, likely play a role in their differences

581 and also strongly influence the relationships globally. Although there is evidence that leaves

582 can phenotypically respond to climate change rapidly (Royer et al., 2009b; Chitwood et al.,

583 2016), there is clearly a genetic control on leaf shape and tooth characters (reviewed in

584 Chitwood and Sinha, 2016). Additionally, there are many families of plants that are

585 overwhelmingly toothed (e.g., Betulaceae, Juglandaceae) or untoothed (Lauraceae, Myrtaceae).

586 However, in Viburnum there are evolutionary correlated shifts in leaf shape and leaf tooth

587 morphology that are coincident with climate (Schmerler et al., 2012), suggesting that in at least

588 some taxa, leaf physiognomy responds to climate on evolutionary timescales.

$589 \quad$ More generally, the phylogenetic composition of a flora strongly can strongly influence

590 leaf physiognomy (Little et al., 2010). There appears to be a significant phylogenetic signal in

591 the relationship between leaf margin and MAT (Jones et al., 2009; Little et al., 2010; Hinojosa et

592 al., 2011) and, using a restricted dataset of 17 sites from the eastern United States and Central

593 America, in the relationship between DiLP characters and MAT as well (Little et al., 2010). Little

594 et al. (2010) also found that phylogenetic generalized least squares analysis that included

595 phylogenetic information improved the ability to predict margin state (toothed vs. entire) from

596 MAT, but with much larger uncertainty and a flatter regression slope. Based on these results,

597 Little et al. (2010) argue that LMA is so strongly affected by phylogenetic bias that it should not

598 be used. However, although there is phylogenetic signal in leaf traits, there is a global

599 relationship between leaf traits and climate (Peppe et al., 2011; Yang et al., 2015) suggesting

600 there is likely geographic and evolutionary sorting of taxa and preferred plant morphology 
601 relative to climate. Further, recent work by Lawing et al. (2016) suggests that the work of Little

602 et al. (2010) may be affected by phylogenetic autocorrelation and that their conclusions may not

603 be valid unless the geographic distribution of tree species also has strong phylogenetic inertia,

604 which seems unlikely given the rapid movement of plants in response to changing climate in the

605 Quaternary and today (e.g., Comes and Kadereit, 1998; Davis and Shaw, 2001; Kelly and

606 Goulden, 2008). However, if plant communities and/or species are in climate disequilibrium

607 (e.g., Svenning and Sandel, 2013; Rokataorinivo et al., 2013), there is the potential for

608 paleoclimate to have influenced modern plant distributions, and thus modern leaf trait-climate

609 relationships, which would considerably confound leaf physiognomic based paleoclimate

610 estimates. Regardless, phylogenetic history likely plays an important role in influencing climate-

611 leaf physiognomy relationships, and future work should focus on incorporating phylogeny into

612 future leaf physiognomic methods.

613 Plant growth habit and leaf life-span also influences leaf physiognomy. In particular,

614 deciduous taxa are more likely to be toothed than evergreen taxa (Peppe et al., 2011; Royer et

615 al., 2012) and leaf life-span (deciduous vs. evergreen) also influences tooth size and number

616 (Peppe et al., 2011). Thus, the growth habits of species within a plant community likely has a

617 strong influence on leaf physiognomy. As an example, floras from the Southern Hemisphere

618 tend to have more species that are evergreen relative to Northern Hemisphere floras; therefore,

619 it is possible that leaf life-span plays a significant role in driving the higher percentage of

620 untoothed species in the Southern Hemisphere (e.g., Upchurch and Wolfe, 1987; Greenwood et

621 al., 2004; Peppe et al., 2011). Using a data set of species, instead of sites which all of the leaf

622 physiognomic calibrations are optimized for, Royer et al. (2012) found that the inclusion of leaf

623 thickness and deciduousness with other DiLP variables and a multiple linear regression model

624 of leaf thickness, deciduousness, and leaf margin reduced the standard errors of both models

625 predictions of MAT. Leaf thickness and deciduousness are not measureable in fossils, but leaf

626 mass per area, which is a proxy for leaf life-span (Royer et al., 2007), can be estimated. The 
627 incorporation of leaf mass per area into a model with other DiLP characters also reduces the

628 standard error of the models prediction of MAT (Royer et al., 2012). These preliminary results

629 suggest that although plant ecology clearly has an effect on leaf physiognomy, its incorporation

630 into paleoclimate models might improve the accuracy and precision of the paleoclimate models.

Nearest living relative methods: The geographic distributions of plants are strongly

633 influenced by their environmental and climatic tolerances (e.g., Merriam, 1894; Küchler, 1964;

634 Holdridge, 1967; Whittaker, 1975). Under the assumption that the climatic tolerances of fossil

635 taxa and fossil plant assemblages are similar to their modern "nearest living relatives" (NLR), for

636 more than 100 years paleobotanists have used this information to estimate ancient climate

637 based on fossil plant assemblages (e.g., Heer, 1870, 1878b, a, 1882; Chaney, 1938; Axelrod,

638 1948, 1952; MacGinitie, 1953; Axelrod and Bailey, 1969; Hickey, 1977; Kerhsaw and Nix, 1987;

639 Mosbrugger and Utescher, 1997). Probably beginning with the work of Heer (e.g., 1870, 1878b,

640 a, 1882), numerous NLR qualitative and quantitative methods have been developed and applied

641 primarily to Cenozoic floras. Both qualitative and quantitative NLR methods use the climatic

642 and ecological requirements of extant plant taxa, which means that these methods rely upon

643 accurate taxonomic identification of plant fossil material. Additionally, NLR methods are not

644 limited to woody dicot angiosperm leaves alone, and any reliably identified plant organ can be

645 utilized.

Qualitative NLR methods rely on individual indicator taxa to derive paleoclimate and

647 paleoenvironment from a fossil flora. For example, the occurrence of palms in a fossil flora

648 would be used to infer warm and wet conditions with cold months above freezing because the

649 palm family Arecaceae is found predominately in tropical to sub-tropical regions with limited to

650 no winter freezing (e.g., Larcher and Winter, 1981; Wing and Greenwood, 1993; Greenwood

651 and Wing, 1995). However, a considerable limitation of these qualitative NLR approaches is 
652 that they do not provide quantitative estimates of paleoclimate (i.e., a MAT or MAP prediction)

653 and the accuracy of the paleoclimate interpretation can be strongly influenced by taphonomic

654 removal of important indicator taxa as well as the level of taxonomic identification of the 655 indicator taxa.

Quantitative NLR methods build on the indicator taxa approach to quantitatively estimate

657 paleoclimate. Originally quantitative NLR methods used a few selected fossil taxa and

658 assessed their overlapping climate preferences, which resulted in broad "coexistence intervals"

659 that were used to estimate paleoclimate (e.g., Grichuk, 1969; Hickey et al., 1988; Zagwijn and

660 Hager, 1987). This approach was modified independently first as bioclimatic analysis (Kerhsaw

661 and Nix, 1987; Greenwood et al., 2003, 2005), and then as the coexistence approach (CA) of

662 Mosbrugger and Utescher (1997). Other NLR methods also use the same fundamental

663 premise, but assess the climatic ranges and/or distributions differently (e.g., Thompson et al.,

664 2012; Harbert and Nixon, 2015). All NLR methods have four primary assumptions: (1) there are

665 modern taxa that are systematically closely related to identified fossil taxa (i.e., their "nearest

666 living relative"); (2) the climate requirements of the fossil taxon are similar to those of the

667 nearest living relatives; (3) the climate tolerances of the nearest living relatives can be derived

668 from its modern distribution; and (4) the climate data for the nearest living relatives is good

669 quality (Mosbrugger and Utescher, 1997; Utescher et al., 2014).

670 In CA all identified fossil taxa are conferred to nearest living relatives. The climatic

671 tolerances of each fossil's nearest living relative are then compared to find an interval where all

672 nearest living relatives could coexist (Fig. 4). The climatic ranges of many vascular plant taxa

673 have been compiled in the Palaeoflora Database (PFDB; www.palaeoflora.de), which is the

674 dataset used for CA. Individual taxa that do not overlap with the rest of the taxa from a site are

675 considered outliers and are removed from the analysis. This subjective removal of outliers has

676 come under criticism (Grimm and Denk, 2012; Grimm et al., 2015; Grimm and Potts, 2016). CA 
677 has been used to reconstruct seven different aspects of temperature and precipitation: MAT,

678 warm month mean temperature, cold month mean temperature, MAP, monthly minimum

679 precipitation, monthly maximum precipitation, and warm month mean precipitation and has a 680 reported precision of $0.1^{\circ} \mathrm{C}$ and $1 \mathrm{~mm}$ precipitation (Mosbrugger and Utescher, 1997). This 681 uncertainty is only the analytical uncertainty of the CA calculation for the coexisting climatic 682 range, and thus is artificially precise and considerably underestimates the total uncertainty of 683 the climate estimate.

Another quantitative NLR method is Bioclimatic Analysis (Kershaw and Nix, 1987;

688 Kershaw, 1997). Just as in CA, in Bioclimatic Analysis fossil taxa are conferred the nearest 689 living relatives, which are compared to determine the climate interval where all of the nearest 690 living relatives could coexist originally using the PFDB and more recently using climatic ranges 691 of taxa using the Global Biodiversity Information Facility (GBIF, http://www.gbif.org/) and the 692 WorldClim global climate models (Hijmans et al., 2005). However, unlike CA, which uses the 693 entire climatic range of all taxa to calculate a climatic variable, Bioclimatic Analysis initially 694 limited coexistence intervals to the $10^{\text {th }}$ (lower limit) to $90^{\text {th }}$ (upper limit) or $5^{\text {th }}$ to $95^{\text {th }}$ percentile 695 values of the total climatic range for all of the nearest living relative taxa (Kershaw and Nix, 696 1988; Kershaw, 1997; Greenwood et al., 2003, 2005). Subsequent iterations of bioclimatic 697 analysis, however, calculated the estimate as the mean value of the $10^{\text {th }}$ and $90^{\text {th }}$ percentile of 698 the maximum and minimum values across all taxa recorded in a sample, with the total range 699 between these plotted as an "error bar" (e.g., Greenwood, et al., 2005; Eldrett et al., 2009, 2014; 700 Pross et al., 2012; Smith et al., 2012; Reichgelt et al., 2013). 
The mutual climatic range (MCR) method estimates paleoclimate from the present

702 climatic tolerance ranges of the nearest living relative of fossil taxa and originally was

703 methodologically nearly identical to CA (Sinka and Atkinson, 1999; Sharpe, 2002). More

704 recently, Thompson et al. (2012) modified the method and currently MCR uses factor-analysis

705 based climate space to plot coldest month temperature against coldest month precipitation and

706 warmest month temperature against warmest month precipitation and the estimated

707 temperature and precipitation for a given time of year (i.e., coldest month, warmest month) is

708 made based on where the climate space overlaps. The MCR method can only be applied to the

709 Quaternary and has only been applied to a few fossil assemblages (Thompson et al., 2012).

710 Applications to modern coleopteran assemblages demonstrates the estimates made using MCR

711 are conservative when compared to meteorological data, but that the method has systematic

712 biases (winter estimates too warm, summer estimates to cool in Britain) (Thompson et al.,

713 2012). Additionally, if neither the absence nor proportion of taxa in the flora can be used to

714 delimit a smaller climatic range, MCR estimates an overly large climatic range (Thompson et al., 715 2012).

716 Climate Reconstruction Analysis using Coexistence Likelihood Estimation (CRACLE) is

717 a new quantitative NLR method that uses global scale specimen collection data to infer species

718 climate tolerance by calculating the maximum joint likelihood of species coexistence (Harbert

719 and Nixon, 2015). CRACLE uses species distribution data from specimen collections obtained

720 from the GBIF and the WorldClim global climate models (Hijmans et al., 2005) to determine

721 species-climate tolerance profiles. When compared to other quantitative NLR methods, MAT

722 estimates made using CRACLE are more accurate and precise suggesting this method may

723 offer considerable improvements over other NLR approaches. However, unless modified,

724 CRACLE is only applicable to the Holocene and late Pleistocene because it requires modern

725 geographic distributions of fossil taxa to make climatic estimates. Additionally, a major limitation

726 of CRACLE is that for it to be applied to the fossil record, it assumes realized niche stasis, which 
727 has been demonstrated to be invalid (e.g., Jackson and Overpeck, 2012; Veloz et al., 2012),

728 and that plant communities are in equilibrium with climate, which also may not always be a valid 729 assumption (e.g., Svenning and Sandel, 2013; Rokataorinivo et al., 2013).

732 rely heavily on accurate climate data for the distribution of the living relative, and precise

733 taxonomic identification. However, resolution of climate estimates decreases at higher

734 taxonomic levels: species-level analyses tend to produce narrow climate intervals, while family-

735 level analyses tend to produce wide climate intervals. Additionally, species turnover within a

736 genus that leads to niche shifts and changes in realized niches through time (e.g., Veloz et al.,

737 2012), are not captured be this approach. This is a problem when trying to apply NLR methods

738 to the fossil record because while younger fossil floras, such as those from the Quaternary,

739 often have a NLR identified at the genus or even species level, older fossil floras, such as those

740 from the Paleogene and Neogene, are often associated with a NLR at the genus or family level

741 where climate intervals are larger and assumptions about the relative stasis of modern climatic

742 distributions of a genus or family may not be appropriate. As a result, NLR methods are

743 typically restricted to Cenozoic floras, though the methods have sometimes been used on

744 assemblages from the late Cretaceous (e.g., Mosbrugger and Utescher, 1997; Utescher et al.,

745 2014; Fletcher et al., 2014).

746 Although NLR methods, and in particular CA, have been applied to a large number of

747 Cenozoic floras (e.g., Utescher et al., 2014), they have recently come under major criticism

748 based on their assumptions about species distributions, the lack of statistical framework, and

749 how climate variables are calculated for past plant communities based on modern plant

750 distributions (Grimm and Potts, 2016). Additionally, there are significant issues with the PFDB,

751 which is used in CA. Studies by Grimm and Denk (2012), Grimm et al. (2015) and Grimm and 
752 Potts (2016) have shown that the MAT ranges in the PFDB are incorrect when compared to

753 climate stations or WorldClim (Hijmans et al., 2005) and even when using corrected climate

754 data the precision of MAT ranges was between $5-10^{\circ} \mathrm{C}$ (Grimm and Denk, 2012). These

755 criticisms raise major questions about the ability of quantitative NLR methods to accurately and

756 precisely reconstruct the paleoclimate of ancient plant communities.

757

758

759

760

761

762

763

764

765

766

767

768

769

770

771

772

773

774 775 (Shipley et al., 2006).

776

777

In addition to a relationship between leaf traits and climate, there are a suite of leaf structural and functional traits that are correlated to each other and to environmental gradients. This covariation of leaf traits is known as the leaf economic spectrum (LES; Wright et al., 2004; Wright et al., 2005; Reich, 2014). The LES is a framework for organizing leaf functional ecology, which reflects a series of trade-offs among leaf traits that are related to carbon balance. Plants on the "fast-return" end of the spectrum, characterized by rapid resource acquisition, typically have a short leaf life-span (less than 12 months), high photosynthetic and respiration rates, low leaf mass per area $\left(\mathrm{M}_{\mathrm{A}}\right)$, high nutrient concentrations (principally nitrogen and phosphorus), and fast growth rates, while the inverse is true for plants with slow resource acquisition on the "slow-return" end of the spectrum (Reich et al., 1997; Westoby et al., 2002; Diaz et al., 2004; Wright et al., 2004; Wright et al., 2005; Reich, 2014). The interrelationships between these traits are largely independent of phylogeny in seed plants (Ackerly and Reich, 1999), have been observed in all vascular plant groups (Wright et al., 2004; Karst and Lechowicz, 2007; Peppe et al., 2014) and probably reflect evolutionary trade-offs in leaf design to maximize resource acquisition vs. performance for the environment in which a plant is living

Recently, researchers have suggested that venation networks are linked to the LES either as the underlying determinant of leaf mass per area, leaf life-span, carbon assimilation 
778 rate, and nitrogen concentration ("vein origin" hypothesis; Blonder et al., 2011; Blonder et al.,

779 2013; Blonder et al., 2014a) or that venation networks are only one axis of many that determine

780 hydraulic conductance and carbon economics, and in turn the plant's relative growth rate ("flux

781 trait network" hypothesis; Sack and Scoffoni, 2013; Sack et al., 2013; Sack et al., 2014).

782 Regardless of which hypothesis is correct, both highlight the importance of vein networks in the 783 LES.

$784 \quad$ While in modern leaves these LES variables are easily measured, they cannot be 785 directly measured in fossil leaves. Instead a series of different proxies based on features that 786 are measureable in fossil leaves, such as leaf area, petiole width, and vein density, have been 787 developed to estimate leaf mass per area $M_{a}$, leaf life-span (LLS), carbon assimilation rate, and 788 respiration rate (e.g., Brodribb et al., 2007; Royer et al., 2007; Boyce et al., 2009; Brodribb and 789 Feild, 2010; Royer et al., 2010; Blonder et al., 2011; Feild et al., 2011b; Royer et al., 2012; Sack 790 and Scoffoni, 2013; Sack et al., 2013; Blonder and Enquist, 2014; Peppe et al., 2014; Sack et 791 al., 2014). These reconstructed LES variables can then be used to reconstruct aspects of the 792 paleoecology of the fossil plant (e.g., leaf life-span, hydraulic conductance), as well as other 793 features of the ecosystem and environment in which the plant lived. Since the majority of these 794 methods are developed based on relationships within the LES, they are applicable across a 795 variety of plant groups and can be used throughout the geologic record (e.g., Royer et al., 2007; 796 Boyce et al., 2009; Brodribb and Feild, 2010; Royer et al., 2010; Blonder et al., 2011; Feild et 797 al., 2011b; Royer et al., 2012; Blonder et al., 2014b; Crifo et al., 2014; Peppe et al., 2014), 798 though some aspects of the LES, such as carbon assimilation and respiration rates are probably 799 heavily dependent on past levels of atmospheric $\mathrm{CO}_{2}$ and $\mathrm{O}_{2}$ (e.g., De Boer et al., 2012;

800 McElwain et al., 2016). 
Peppe et al. - Paleoclimate and paleoecology using fossil leaves

Most leaf economic spectrum traits cannot be directly measured in fossils. However, a

806 proxy for $M_{a}$, which is a core LES character and also correlates strongly with leaf thickness and

807 leaf life-span (Wright et al., 2004; Royer et al., 2012), has been developed that is applicable to

808 fossil plants (Royer et al., 2007; Royer et al., 2010; Peppe et al., 2014). The method uses the

809 scaling relationship between petiole width (PW), leaf area (A), and $M_{a}$. The relationship

810 between $\mathrm{PW}$ and $A$ to $M_{a}$ is based on the biomechanics of the leaves since heavier leaves need

811 more support, which necessitates larger, thicker petioles (Royer et al., 2007; Royer et al., 2010;

812 Peppe et al., 2014). Leaves with high $\mathrm{M}_{\mathrm{a}}$ are more commonly evergreen and thicker, which in

813 addition to providing structural support also allows long-term nutrient transport (Wright et al.,

814 2004).

815 Proxies for leaf mass per area have been developed for all woody dicot angiosperms

816 (Royer et al., 2007), herbaceous angiosperms and broadleaf gymnosperms (Royer et al., 2010),

817 and ferns (Peppe et al., 2014). Each of these groups has significantly different scaling

818 relationships between $\mathrm{PW}$ and $\mathrm{A}$ to $\mathrm{M}_{\mathrm{a}}$ and the relationships in angiosperms and broadleaf

819 gymnosperms are explained by a different biomechanical model than ferns. The relationships

820 between area normalized $\mathrm{PW}$ and $\mathrm{M}_{\mathrm{a}}$ in angiosperms and broadleaf gymnosperms are best

821 explained by modeling a leaf as a pole supporting a singular mass and assumes that the cross-

822 sectional area of the petiole is proportional to leaf mass (Royer et al., 2007; Royer et al., 2010).

823 The relationships between $\mathrm{PW}$ and $\mathrm{A}$ to $\mathrm{M}_{\mathrm{a}}$ in ferns are best explained by a cantilever beam

824 model that assumes the petiole width and length are independent, that petiole shape is

825 relatively invariant, and that the leaf mass is proportional to the flexural rigidity of the entire

826 petiole (Peppe et al., 2014).

827 The $M_{a}$ of fossil leaves can be used to estimate a number of paleoecological variables.

828 First, greater $M_{a}$ is correlated with longer leaf life-span and can be used to reconstruct the leaf

829 life-span of a fossil flora (Royer et al., 2007; Royer et al., 2010; Peppe et al., 2014). Fossil 
830 leaves with a $M_{a}<\sim 87 \mathrm{~g} \mathrm{~m}^{-2}$ can be broadly categorized as deciduous and those with a $M_{a}>$

$831 \sim 129 \mathrm{~g} \mathrm{~m}^{-2}$ can be broadly categorized as evergreen, with the transition between predominately

832 deciduous to predominately evergreen occurring at $\sim 111 \mathrm{~g} \mathrm{~m}^{-2}$ (Royer et al., 2007). The

833 variance in $\mathrm{M}_{\mathrm{a}}$ and leaf life-span can also be used to infer seasonality in paleoecosystems with

834 greater variance in $M_{a}$ in plant populations related to greater seasonality (Wright et al., 2005).

835 Additionally, the distribution of $\mathrm{M}_{\mathrm{a}}$ of a flora also appears to be environmentally specific (Royer

836 et al., 2010), suggesting that the distribution of $\mathrm{M}_{\mathrm{a}}$ in a fossil flora can be compared to modern

837 distributions and used as a proxy for environment. Finally, $M_{a}$ correlates with leaf nitrogen

838 content (Royer et al., 2005), and could potentially be used as a proxy for percent nitrogen,

839 which could be used to infer nutrient cycling in fossil forest ecosystems.

840 The interaction of plants and their herbivores has a long geologic record and can be

841 used to infer a variety of ecological variables (Labandeira and Currano, 2013). Reconstructions

842 of $M_{a}$ combined with measurements of insect-plant interactions via their feeding traces can be

843 used to reconstruct aspects of plant ecology such as nutrient content and ecosystem

844 disturbance (Royer et al., 2007; Currano et al., 2008; Currano et al., 2011). Leaves with greater

$845 M_{a}$ have lower diversity, lower density, and lower area removed by insect herbivores when

846 compared to leaves with low $M_{a}$ (Coley, 1983; Royer et al., 2007). This relationship between

847 insect damage and $M_{a}$ is probably because leaves with high $M_{a}$ are typically thicker and/or

848 tougher, possess a greater amount and concentration of chemical deterrents, and have lower

849 leaf nitrogen content, which makes them less nutritious and less palatable for insect herbivores

850 (Coley, 1983; Royer et al., 2007). Additionally, changes in the diversity and density of insect

851 feeding traces can be used to infer large-scale changes in ecology following ecological

852 disturbances, including changes in climate and recovery after mass extinction events (e.g. Wilf

853 et al., 2006: Currano et al., 2008: Currano et al., 2011: Donovan et al., 2016).

854 Recent studies have suggested a link between vein networks and the LES (Blonder et 855 al., 2011; Blonder et al., 2013; Blonder et al., 2014); however, this remains controversial (e.g., 
856 Sack and Scoffoni, 2013; Sack et al., 2013; Sack et al., 2014; Li et al., 2015). If there is a

857 relationship between vein networks and the leaf economic spectrum, measurements of vein

858 networks in fossil plants could be used to reconstruct other LES variables, such as leaf life-span

859 and $M_{a}$, which in turn would allow for paleoecological reconstruction. These proxies are in

860 development, but offer considerable promise. In addition to its relationship to the LES, vein

861 networks, and specifically vein density, is a proxy for water use efficiency and gas exchange,

862 making it a powerful tool for assessing gas and water exchange capacity of plants (Sack et al.,

863 2005; Sack and Frole, 2006; Brodribb et al., 2007; Boyce et al., 2009; Brodribb and Feild, 2010).

864 For example, angiosperms have much higher vein densities than plants from all other groups,

865 living or extinct, which allows angiosperms to have much higher rates of transpiration (Boyce et

866 al., 2009). This connection between high vein density and high rates of transpiration in

867 angiosperms has been used to infer that the evolution of angiosperms and their increase in

868 maximum leaf vein density through the Cretaceous enabled the evolution and expansion of

869 tropical rain forests, because transpiration rates in other plant groups are too low to maintain the

870 precipitation abundance and evenness necessary for tropical rainforest ecosystems (Boyce et

871 al., 2009; Boyce et al., 2010; Feild et al., 2011a). The distribution of vein densities within a flora

872 differs significantly between canopy and understory plants and between sites with different

873 forest structures (Crifo et al., 2014). Thus, it is possible to infer ancient forest structure, and its

874 constituent understory and canopy taxa, from the range of vein densities within a fossil flora

875 (Crifo et al., 2014).

\section{Shortcomings and limitations of paleoecological methods}

$878 \quad$ Methods of paleoecological reconstruction are very powerful tools for assessing aspects

879 of plant ecology (e.g., leaf life-span, hydraulic conductance) and a ecosystem's environment

880 (e.g., ecosystem disturbance, forest structure); however, these methods are relatively new and

881 have been not been widely applied. The primary reason for this is that they require excellent 
882 preservation of venation (vein density proxies), and the entire leaf area and at least part of the

883 leaf petiole ( $\mathrm{M}_{\mathrm{A}}$ proxies). Due to taphonomic constraints, these proxies cannot be applied to

884 many fossil floras, or in some cases, can only be applied to the best preserved specimens

885 within a flora such that the reconstructed ecological variables may not be representative of the

886 entire flora. As an example, Blonder et al. (2014b) were only able to analyze $<20 \%$ of more

887 than 6,000 collected fossil specimens, suggesting the potential for significant taphonomic biases

888 in leaf vein density analyses. Additionally, though there appears to be a relationship between

889 leaf vein density and forest structure (Crifo et al., 2014) and $\mathrm{M}_{\mathrm{A}}$ and environment (Royer et al.,

890 2010), these relationships are based on relatively limited datasets with small sample sizes.

891 Thus, it's unclear if these relationships are representative globally and to all ecosystems.

892

893

894

APPLICATION OF PALEOCLIMATE AND PALEOECOLOGICAL PROXIES

895

Leaf physiognomic methods for reconstructing paleoclimate have been applied

hundreds, if not thousands of times to fossil floras from the Cretaceous through the Quaternary, and leaf trait methods for reconstructing paleoecology have begun to be applied to fossil plants

897 through Earth history. The following is a brief example of an application of these methods for 898 reconstructing paleoclimate and paleoecology by Michel et al. (2014) that made it possible to 899 reconstruct the climate and to determine the climatic, environmental, and ecological biome of 900 the fossil site. The study of Michel et al. (2014) documented a diverse ssemblage of fossil 901 vertebrates, leaves, and tree stump and root casts and used the fossil data to reconstruct the 902 paleoclimate and paleoenvironment of the Early Miocene R3 fossil site on Rusinga Island, 903 western Kenya. The R3 fossil site is of particular interest because of the co-occurrence of 904 multiple species of Early Miocene catarrhines, including Dendropithecus macinnesi and Ekembo 905 heseloni, as well as several vertebrate fossil taxa that suggest a more closed environment.

906 Prior to the work of Michel et al. (2014), the paleoenvironment of the site was relatively poorly 907 constrained. Michel et al. (2014) mapped a series of fossil tree stump casts of varying diameter 
908 preserved within the same stratigraphic layer across the R3 site. Based on the density of the

909 tree stump casts across the landscape, they reconstructed the ecosystem as a dense, closed-

910 canopy, multi-storied forest. Abundant fossil leaves were found in a thing mudstone layer

911 stratigraphically directly above the fossil tree stump casts. The flora was made up of 29

912 morphotpyes, which can be considered a rough proxy for biological species (see Ash et al.,

9131999 and Peppe et al., 2008 for a review of the morphotype method), representing 27

914 dicotyledonous (dicot) and 2 monocotyledonous angiosperms. The dicots were used to

915 reconstruct the paleoclimate and paleoecology of the site.

916

PLACE FIGURE 5 ABOUT HERE; WIDTH = ONE PANEL

The mean annual temperature and mean annual precipitation of the site was

920 reconstructed using LMA and LAA, respectively (Fig. 5). Mean annual temperature

921 reconstructed using the LMA regressions of Wolfe (1979), Miller et al. (2006), Kowalski and

922 Dilcher (2003), and Peppe et al. (2011) ranged between $22.6^{\circ} \mathrm{C}$ and $34.5^{\circ} \mathrm{C}$ (Fig. 5). Mean

923 annual precipitation reconstructed using the LAA regression of Wilf et al. (1998), Gregory-

924 Wodzicki (2000), Jacobs and Herendeen (2004) and Peppe et al. (2011) ranged from 1,394 mm

925 to $2,618 \mathrm{~mm}$ (Fig. 5). Wet month precipitation estimates using the method of Jacobs and

926 Herendeen (2004) indicate that there was relatively little precipitation during the dry season.

927 This evidence for seasonality is also supported by analyses of the paleosols at the R3 site. The

928 paleoclimate reconstructions for the site indicate a tropical seasonal forest biome (Fig. 5;

929 Whittaker, 1975). Interestingly, the forest density evidence for the R3 site are very similar to

930 modern tropical seasonal forests that support medium and large bodied primate communities,

931 such as Barro Colorado Island (BCl), Panama and Ituri Forest, Democratic Republic of Congo.

932 Only univariate methods were utilized on the R3 flora because, as discussed above, the leaf 933 physiognomic space of the fossil flora is not captured by the modern DiLP dataset (Fig. 3). This 
934 demonstrates one of the limitations of the existing multivariate methods, and the difficulty of

935 reconstructing the paleoclimate of African fossil floras.

Leaf mass per area was reconstructed for seventeen of the twenty seven dicot

940 morphotypes from R3 (Fig. 6, 7). Leaf mass per area reconstructions for the flora indicate that

941 the species were predominantly evergreen, but that there was an important component of

942 deciduous taxa (Fig. 6). The distribution of $\mathrm{M}_{\mathrm{a}}$ at the site is most similar to non-riparian sites

943 (Fig. 7), which is unsurprising given the sedimentological and paleosols evidence from the site.

944 The paleoclimate reconstructions for the flora are most similar to $\mathrm{BCl}$ site (MAT $=26.5^{\circ} \mathrm{C}, \mathrm{MAP}$

$945=2620 \mathrm{~mm}$ ), and the distribution of $\mathrm{M}_{\mathrm{a}}$ at the sites is similar, though $\mathrm{BCl}$ has a higher proportion

946 of species low $M_{a}$ than the R3 flora (Fig. 7D). The R3 flora is also somewhat similar to the non-

947 riparian, wet tropical rainforest of Buena Vista, Puerto Rico, though the wet tropics site has a

948 larger proportion of species with much higher $M_{a}$ than reconstructed for the R3 flora (Fig. 7E).

949 Similar to the paleoclimate estimates, the $M_{a}$ reconstructions for R3 also suggest a non-riparian

950 tropical seasonal forest or tropical rainforest biome.

\section{PLACE FIGURE 7 ABOUT HERE; WIDTH = TWO PANELS}

955 leaves indicate a tropical seasonal forest biome and a warm and seasonally wet climate (Fig. 5,

$9566,7)$. These results are also in agreement with reconstructions of the forest density and

957 paleonvironmental reconstructions based on the paleosols at the site and the composition of the

958 vertebrate fauna. Together, the multiproxy evidence presented by Michel et al. (20014)

959 indicates that the R3 fossil locality sampled a widespread, dense, multistoried, closed-canopy 
960 tropical seasonal forest set in a warm and seasonally wet climate. When combined with the

961 primate fossil record from the R3 site, the paleoclimate and paleoecological results of Michel et

962 al. (2014) demonstrate the importance of forested environments in the evolution of early apes in

963 Africa. The Michel et al. (2014) study is an example of the power and utility of combining fossil

964 leaf based estimates of paleoclimate and paleoecology to reconstruct a terrestrial ecosystem,

965 and is a good model for fossil leaf based research focused on terrestrial ecosystem and climate 966 reconstruction.

\section{FUTURE RESEARCH DIRECTIONS}

Fossil plants, and particularly fossil leaves, are powerful tools for reconstructing

971 paleoclimate and paleoecology. However, despite the power of the paleoclimate and

972 paleoecology methods that can be applied to fossils, they have important limitations.

973 One of the most important potential shortcomings of leaf physiognomic methods is the

974 possible influence of phylogeny and life history on leaf trait-climate relationships. Recently, the

975 vertebrate paleontology community has begun to develop a series of trait-based approaches

976 that use relationships between functional traits and environment to reconstruct climate and

977 assess the responses of faunal communities to environmental change called ecometrics (e.g.,

978 Eronen et al., 2010a; Eronen et al., 2010b; Polly et al., 2011; Lawing et al., 2012; Polly and

979 Sarwar, 2014; Lawing et al., 2016). These methods have addressed potential issues related to

980 phylogenetic influences on functional traits by resampling techniques and by applying

981 phylogenetic corrections to the datasets (Eronen et al., 2010b; Lawing et al., 2012; Polly and

982 Sarwar, 2014; Lawing et al., 2016). The utilization of these types of methods when revising and

983 developing new leaf physiognomic methods for reconstructing paleoclimate has considerable

984 potential and is an important future research direction. Additionally, as noted above, the leaf

985 physiognomic-climate relationships are different between the Northern and Southern 
986 Hemispheres. The development of new calibration datasets that incorporate more floras from 987 the Southern Hemisphere, and particularly Africa and South America, and from tropical regions 988 will add phylogenetic diversity to the calibration datasets and may make it possible to ascertain 989 the driver behind the hemispheric differences, especially if phylogenetic corrections are applied 990 to the datasets.

991 Leaf life-span also has an important effect on leaf trait-climate relationships. Royer et al. 992 (2012) found that the incorporation of leaf thickness, deciduousness, and $\mathrm{M}_{\mathrm{A}}$ into species993 specific leaf physiognomic models reduced the standard errors of the models. However, this 994 result was based on a species-based dataset, instead of a site-based calibration, on which all 995 leaf physiognomic models are based. Thus, it's uncertain if these results are broadly applicable 996 to existing leaf physiognomic models. Using a dataset of taxa from 17 floras from a range of 997 MATs, Blonder and Enquist (2014) demonstrated a relationship between vein density and MAT, 998 which they used to develop a predictive model for MAT. However, the relationships between 999 vein density and MAT were different in temperate and tropical floras, such that they developed 1000 one model with different parameter values for temperature floras and tropical floras. Taken 1001 together, the results of Royer et al. (2012) and Blonder and Enquist (2014) suggest that the 1002 incorporation of functional traits, such as vein density and $\mathrm{M}_{\mathrm{A}}$, into leaf physiognomic models 1003 could improve their precision and accuracy and are an interesting research direction to pursue. 1004

1008 leaves (e.g., Cope et al., 2012; Corney et al., 2012a; Corney et al., 2012b; Price et al., 2012;

1009 Green et al., 2014; MacLeod and Steart, 2015; Wilf et al., 2016). Automated measurements of 1010 leaf size and shape would eliminate ambiguities in leaf trait scoring, increase scoring 1011 throughput, make it easier to measure continuous variables, and potentially help aid in the 
1012 identification of fossil plants. The potential of automated or semi-automated leaf trait scoring 1013 and identification is an exciting new development that has the potential to revolutionize the way 1014 leaf traits are scored and help to significantly improve leaf trait-climate and ecological proxies. 1015 One of the fundamental shortcomings of leaf-based climate reconstruction is that we still 1016 do not understand the physiological and/or evolutionary mechanisms that drive the empirical 1017 relationships observed between leaf physiognomy and climate. As a result leaf physiognomic 1018 proxies are empirically derived and traits used for extrapolation may not have a direct functional 1019 link to climate or ecology and/or may be strongly driven by phylogeny and life history. This 1020 might lead to biased paleoclimate and paleoecological estimates, particularly in deep time.

1021 Research focused on the evolution of leaf form and on the genetic underpinnings of leaf shape 1022 and development is making significant strides towards addressing this shortcoming (e.g., Pérez1023 Pérez et al., 2010; Schmerler et al., 2012; Edwards and Donoghue, 2013; Chitwood et al., 2014; 1024 2016; Dkhar and Pareek, 2014; Rodriguez et al., 2014; Vaughan, 2015; Chitwood and Sinha, 1025 2016; Coneva et al., 2017). A more complete understanding of the genetic controls on leaf size 1026 and shape and the drivers of leaf shape evolution will make it possible for us to better 1027 understand how environment and climate influence leaf physiognomy, as well as provide a 1028 basis for understanding plant species' distributions on climatic gradients. This will allow for the 1029 development of phylogenetically and physiologically informed plant-based paleoclimatic and 1030 paleoecological proxies, which has the potential to revolutionize the field and our ability to 1031 reconstruct ancient climate and ecology.

\section{ACKNOWLEDGEMENTS}

1035 We would like to thank Denise Su, Scott Simpson, and Darren Croft for inviting us to contribute 1036 to the Latest Methods in Reconstructing Cenozoic Terrestrial Environments and Ecological 1037 Communities workshop and to this special volume. We thank Dana Royer for many helpful 
1038 discussions about these topics and review of this manuscript and David Greenwood for his

1039 helpful and constructive review. This work was supported by the National Science Foundation 1040 (grant EAR-1325552).

\section{REFERENCES CITED}

1043

1044 Ackerly, D. D., and Reich, P. B., 1999, Convergence and correlations among leaf size and 1045 function in seed plants: A comparative test using independent contrasts: American 1046 Journal of Botany, v. 86, no. 9, p. 1272-1281.

1047 Adams, J. M., Green, W. A., and Zhang, Y., 2008, Leaf margins and temperature in the north 1048 american flora: Recalibrating the paleoclimatic thermometer: Global and Planetary 1049 Change, v. 60, no. 3-4, p. 523-534.

1050 Adams, J. S., Kraus, M. J., and Wing, S. L., 2011, Evaluating the use of weathering indices for 1051 determining mean annual precipitation in the ancient stratigraphic record: Palaeogeography, Palaeoclimatology, Palaeoecology, v. 309, no. 3, p. 358-366.

1053 Aizen, M. A., and Ezcurra, C., 2008, Do leaf margins of the temperate forest flora of southern 1054 south america reflect a warmer past?: Global Ecology and Biogeography, v. 17, no. 2, p. $1055 \quad 164-174$.

1056 Ash, A., Ellis, B., Hickey, L. J., Johnson, K. R., Wilf, P., and Wing, S., 1999, Manual of leaf 1057 architecture - morphological description and categorization of dicotyledonous and net1058 veined monocotyledonous angiosperms, Washington D.C., The Leaf Architecture 1059 Working Group, Smithsonian Institution, 65 p.

1060 Axelrod, D. I., 1948, Climate and evolution in western North America during middle Pliocene 1061 time: Evolution, p. 127-144.

1062 -, 1952, A theory of angiosperm evolution: Evolution, p. 29-60. 
Peppe et al. - Paleoclimate and paleoecology using fossil leaves

1063

1064

1065

1066

1067

1068

1069

1070

1071

1072

1073

1074

1075

1076

1077

1078

1079

1080

1081

1082

1083

1084

1085

1086

1087

1088

Axelrod, D. I., and Bailey, H. P., 1969, Paleotemperature analysis of tertiary floras:

Palaeogeography, Palaeoclimatology, Palaeoecology, v. 6, p. 163-195.

Bailey, I. W., and Sinnott, E. W., 1915, A botanical index of Cretaceous and Tertiary climates: Science, v. 41, no. 1066, p. 831-834.

Bailey, I. W., and Sinnott, E. W., 1916, The climatic distribution of certain types of angiosperm leaves: American Journal of Botany, v. 3, no. 1, p. 24-39.

Baker-Brosh, K. F., and Peet, R. K., 1997, The ecological significance of lobed and toothed leaves in temperate forest trees: Ecology, v. 78, no. 4, p. 1250-1255.

Baumgartner, K. A., and Meyer, H. W., 2014, Coexistance climate analysis of the late Eocene Florissant flora, Colorado: Geological Society of America - Abstract with Programs, v. 46, no. 6, p. 490.

Billings, F. H., 1905, Precursory leaf serrations of Ulmus: Botanical Gazette, p. 224-225.

Blonder, B., and Enquist, B. J., 2014, Inferring climate from angiosperm leaf venation networks: New Phytologist, v. 204, no. 1, p. 116-126.

Blonder, B., Nogués-Bravo, D., Borregaard, M. K., Donoghue, I., John, C., Jørgensen, P. M., Kraft, N. J., Lessard, J.-P., Morueta-Holme, N., and Sandel, B., 2015, Linking environmental filtering and disequilibrium to biogeography with a community climate framework: Ecology, v. 96, no. 4, p. 972-985.

Blonder, B., Violle, C., Bentley, L. P., and Enquist, B. J., 2011, Venation networks and the origin of the leaf economics spectrum: Ecology Letters, v. 14, no. 2, p. 91-100.

-, 2014a, Inclusion of vein traits improves predictive power for the leaf economic spectrum: A response to sack et al. (2013): Journal of Experimental Botany, v. 65, no. 18, p. 51095114.

Blonder, B., Royer, D. L., Johnson, K. R., Miller, I., and Enquist, B. J., 2014b, Plant ecological strategies shift across the Cretaceous-Paleogene boundary: PLoS Biol, v. 12, no. 9, p. e1001949. 
Peppe et al. - Paleoclimate and paleoecology using fossil leaves

1089

1090

1091

1092

1093

1094

1095

1096

1097

1098

1099

1100

1101

1102

1103

1104

1105

1106

1107

1108

1109

1110

1111

1112

1113

Blonder, B., Violle, C., and Enquist, B. J., 2013, Assessing the causes and scales of the leaf economics spectrum using venation networks in Populus tremuloides: Journal of Ecology, v. 101, no. 4, p. 981-989.

Boyce, C. K., Brodribb, T. J., Feild, T. S., and Zwieniecki, M. A., 2009, Angiosperm leaf vein evolution was physiologically and environmentally transformative: Proceedings of the Royal Society B: Biological Sciences, v. 276, no. 1663, p. 1771-1776.

Boyce, C. K., Lee, J.-E., Feild, T. S., Brodribb, T. J., and Zwieniecki, M. A., 2010, Angiosperms helped put the rain in the rainforests: The impact of plant physiological evolution on tropical biodiversity 1: Annals of the Missouri Botanical Garden, v. 97, no. 4, p. 527-540.

Brodribb, T. J., and Feild, T. S., 2010, Leaf hydraulic evolution led a surge in leaf photosynthetic capacity during early angiosperm diversification: Ecology Letters, v. 13, no. 2, p. 175183.

Brodribb, T. J., Feild, T. S., and Jordan, G. J., 2007, Leaf maximum photosynthetic rate and venation are linked by hydraulics: Plant Physiology, v. 144, no. 4, p. 1890-1898.

Burnham, R. J., Ellis, B., and Johnson, K. R., 2005, Modern tropical forest taphonomy: Does high biodiversity affect paleoclimatic interpretations?: PALAIOS, v. 20, no. 5, p. 439-451.

Burnham, R. J., Pitman, N. C. A., Johnson, K. R., and Wilf, P., 2001, Habitat-related error in estimating temperatures from leaf margins in a humid tropical forest: American Journal of Botany, v. 88 , no. 6 , p. 1096-1102.

Burnham, R. J., and Tonkovich, G. S., 2011, Climate, leaves, and the legacy of two giants: New Phytologist, v. 190, no. 3, p. 514-517.

Canny, M., 1990, Tansley review no. 22 what becomes of the transpiration stream?: New Phytologist, v. 114, no. 3, p. 341-368.

Chaloner, W. G., and Creber, G. T., 1990, Do fossil plants give a climatic signal?: Journal of the Geological Society, v. 147, no. 2, p. 343-350. 
1114 Chaney, R. W., 1938, Paleoecological interpretations of Cenozoic plants in western North America: The Botanical Review, v. 4, no. 7, p. 371-396.

Chen, W.-Y., Su, T., Adams, J. M., Jacques, F. M., Ferguson, D. K., and Zhou, Z.-K., 2014, Large-scale dataset from China gives new insights into leaf margin-temperature relationships: Palaeogeography, Palaeoclimatology, Palaeoecology, v. 402, p. 73-80.

Chitwood, D. H., Klein, L. L., O'Hanlon, R., Chacko, S., Greg, M., Kitchen, C., Miller, A. J., and Londo, J. P., 2016, Latent developmental and evolutionary shapes embedded within the grapevine leaf: New Phytologist, v. 210, no. 1, p. 343-355.

Chitwood, D. H., Ranjan, A., Martinez, C. C., Headland, L. R., Thiem, T., Kumar, R., Covington, M. F., Hatcher, T., Naylor, D. T., and Zimmerman, S., 2014, A modern ampelography: a

Chitwood, D. H., Rundell, S. M., Li, D. Y., Woodford, Q. L., Tommy, T. Y., Lopez, J. R., Greenblatt, D., Kang, J., and Londo, J. P., 2016, Climate and developmental plasticity: Interannual variability in grapevine leaf morphology: Plant physiology, v. 170, no. 3, p. 1480-1491.

Chitwood, D. H., and Sinha, N. R., 2016, Evolutionary and environmental forces sculpting leaf development: Current Biology, v. 26, p. R297-R306.

1136 Coneva, V., Frank, M. H., de Luis Balaguer, M. A., Li, M., Sozzani, R., and Chitwood, D. H., 2017, Genetic architecture and molecular networks underlying leaf thickness in sesertadapted tomato Solanum pennellii: bioRxiv. 
1139

1140

1141

1142

1143

1144

1145

1146

1147

1148

1149

1150

1151

1152

1153

1154

1155

1156

1157

1158

1159

1160

1161

1162

Cope, J. S., Corney, D., Clark, J. Y., Remagnino, P., and Wilkin, P., 2012, Plant species identification using digital morphometrics: A review: Expert Systems with Applications, v. 39, no. 8 , p. $7562-7573$.

Corney, D., Clark, J. Y., Tang, H. L., and Wilkin, P., 2012a, Automatic extraction of leaf characters from herbarium specimens: Taxon, v. 61, no. 1, p. 231-244.

Corney, D. P., Tang, H. L., Clark, J. Y., Hu, Y., and Jin, J., 2012b, Automating digital leaf measurement: The tooth, the whole tooth, and nothing but the tooth: PloS one, v. 7, no. 8, p. e42112.

Crifo, C., Currano, E. D., Baresch, A., and Jaramillo, C., 2014, Variations in angiosperm leaf vein density have implications for interpreting life form in the fossil record: Geology, v. 42, no. 10 , p. $919-922$.

Christophel, D.C. and Blackburn, D.T., 1978. Tertiary megafossil flora of Maslin Bay, South Australia: a preliminary report. Alcheringa, 2(4), pp.311-319.

Currano, E. D., Jacobs, B. F., Pan, A. D., and Tabor, N. J., 2011, Inferring ecological disturbance in the fossil record: A case study from the Late Oligocene of Ethiopia: Palaeogeography, Palaeoclimatology, Palaeoecology, v. 309, no. 3-4, p. 242-252.

Currano, E. D., Wilf, P., Wing, S. L., Labandeira, C. C., Lovelock, E. C., and Royer, D. L., 2008, Sharply increased insect herbivory during the Paleocene-Eocene Thermal Maximum: Proceedings of the National Academy of Sciences of the United States of America, v. 105, no. 6 , p. $1960-1964$.

Davis, M. B., 1986, Climatic instability, time, lags, and community disequilibrium, in Diamond, J., and Case, T. J., eds., Community ecology: New York, NY, Harper \& Row, p. 269-284.

Davis, M. B., and Shaw, R. G., 2001, Range shifts and adaptive responses to Quaternary climate change: Science, v. 292, no. 5517, p. 673-679. 
1163 De Boer, H. J., Eppinga, M. B., Wassen, M. J., and Dekker, S. C., 2012, A critical transition in leaf evolution facilitated the Cretaceous angiosperm revolution: Nature Communications, v. 3, p. 1221.

Diaz, S., Hodgson, J. G., Thompson, K., Cabido, M., Cornelissen, J. H. C., Jalili, A., MontserratMarta, G., Grime, J. P., Zarrinkamar, F., Asri, Y., Band, S. R., Basconcelo, S., CastroDiez, P., Funes, G., Hamzehee, B., Khoshnevi, M., Parez-Harguindeguy, N., PerezRontoma, M. C., Shirvany, A., Vendramini, F., Yazdani, S., Abbas-Azimi, R., Bogaard, A., Boustani, S., Charles, M., Dehghan, M., de Torres-Espuny, L., Falczuk, V., GuerreroCampo, J., Hynd, A., Jones, G., Kowsary, E., Kazemi-Saeed, F., Maestro-Martinez, M., Romo-Diez, A., Shaw, S., Siavash, B., Villar-Salvador, P., Zak, M. R., and Rapson, G., 2004, The plant traits that drive ecosystems: Evidence from three continents: Journal of Vegetation Science, v. 15, no. 3, p. 295-304.

Dilcher, D., 1973, A paleoclimatic interpretation of the Eocene floras of southeastern North America, in Graham, A., ed., Vegetation and vegetational history of northern Latin America: Amsterdam, Elsevier, p. 39-59.

$1184-, 1980 \mathrm{~b}$, Variation in leaf size with respect to climate in the tropics of the Western Hemisphere: 1185 Bulletin of the Torrey Botanical Club, v. 107, p. 154-162.

1186 Donovan, M. P., Iglesias, A., Wilf, P., Labandeira, C. C., and Cuneo, N. R. 2016. Rapid recovery of Patagonian plant-insect associations after the end-Cretaceous extinction. Nature Ecology and Evolution (1), 0012, doi: 10.1038/s41559-016-0012. 
Peppe et al. - Paleoclimate and paleoecology using fossil leaves

1189

1190

1191

1192

1193

1194

1195

1196

1197

1198

1199

1200

1201

1202

1203

1204

1205

1206

1207

1208

1209

1210

1211

1212

1213

1214

Edwards, E. J., and Donoghue, M. J., 2013, Is it easy to move and easy to evolve? Evolutionary accessibility and adaptation: Journal of Experimental Botany, p. ert220.

Eldrett JS, Greenwood DR, Harding IC, Huber M. 2009. Increased seasonality through the Eocene to Oligocene transition in northern high latitudes. Nature, 459 (7249): 969 - 974, doi:10.1038/nature08069

Eldrett JS, Greenwood DR, Polling M, Brinkhuis H, Sluijs A. 2014. A seasonality trigger for carbon injection at the Paleocene-Eocene Thermal Maximum. Climate of the Past, 10: 759-769, doi:10.5194/cp-10-759-2014

Eronen, J., Puolamäki, K., Liu, L., Lintulaakso, K., Damuth, J., Janis, C., and Fortelius, M., 2010a, Precipitation and large herbivorous mammals i: Estimates from present-day communities: Evolutionary Ecology Research, v. 12, no. 2, p. 217-233.

Eronen, J. T., Polly, P. D., Fred, M., Damuth, J., Frank, D. C., Mosbrugger, V., Scheidegger, C., Stenseth, N. C., and Fortelius, M., 2010b, Ecometrics: The traits that bind the past and present together: Integrative zoology, v. 5, no. 2, p. 88-101.

Feild, T. S., Brodribb, T. J., Iglesias, A., Chatelet, D. S., Baresch, A., Upchurch, G. R., Gomez, B., Mohr, B. A., Coiffard, C., and Kvacek, J., 2011a, Fossil evidence for Cretaceous escalation in angiosperm leaf vein evolution: Proceedings of the National Academy of Sciences, v. 108, no. 20, p. 8363-8366.

Feild, T. S., Sage, T. L., Czerniak, C., and Iles, W. J. D., 2005, Hydathodal leaf teeth of Chloranthus japonicus (Chloranthaceae) prevent guttation-induced flooding of the mesophyll: Plant, Cell \& Environment, v. 28, no. 9, p. 1179-1190.

Feild, T. S., Upchurch Jr, G. R., Chatelet, D. S., Brodribb, T. J., Grubbs, K. C., Samain, M.-S., and Wanke, S., 2011b, Fossil evidence for low gas exchange capacities for early Cretaceous angiosperm leaves: Paleobiology, v. 37, no. 2, p. 195-213.

Fletcher TL, Greenwood DR, Moss PT, Salisbury SW. 2014. Paleoclimate of the Late Cretaceous (Cenomanian-Turonian) portion of the Winton Formation, central-western 
Peppe et al. - Paleoclimate and paleoecology using fossil leaves

1215

1216

1217

1218

1219

1220

1221

1222

1223

1224

1225

1226

1227

1228

1229

1230

1231

1232

1233

1234

1235

1236

1237

1238

1239

Queensland, Australia: new observations based on CLAMP and bioclimatic analysis. Palaios, 29(3): 121 - 128, doi: 10.2110/palo.2013.080

Flynn, A. G., Peppe D. J., Abbuhl, B., Williamson, T.E. 2016. Paleoclimate and Paleoecology of Diverse Early Paleocene Fossil Flora from the San Juan Basin, New Mexico, USA. XIV International Palynologival Congress - X International Organisation of Paleobotany Conference.

Fricke, H. C., and Wing, S. L., 2004, Oxygen isotope and paleobotanical estimates of temperature and $\delta^{18} \mathrm{O}$-latitude gradients over North America during the Early Eocene: American Journal of Science, v. 304, no. 7, p. 612-635.

Gates, D. M., 1980, Biophysical ecology, New York, New York, Springer-Verlag.

Givnish, T. J., 1984, Leaf and canopy adaptations in tropical forests, in Medina, E., Mooney, H. A., and Vasquez-Yanes, C., eds., Physiological ecology of plants of the wet tropics: The Hague, Junk, p. 51-84.

Green, W. A., 2006, Loosening the CLAMP: An exploratory graphical approach to the Climate Leaf Analysis Multivariate Program: Palaeontologia Electronica, v. 9, no. 2, p. 9A: 17p.

Green, W. A., Little, S. A., Price, C. A., Wing, S. L., Smith, S. Y., Kotrc, B., and Doria, G., 2014, Reading the leaves: A comparison of leaf rank and automated areole measurement for quantifying aspects of leaf venation: Applications in Plant Sciences, v. 2, no. 8, p. 1400006.

Greenwood, D. R., 1991, The Taphonomy of Plant Macrofossils. Ch. 7, in SK., D., ed., The Processes of Fossilization: London, Belhaven Press, p. 141-169.

Greenwood, D. R., 1992, Taphonomic constraints on foliar physiognomic interpretations of late Cretaceous and Tertiary paleoclimates: Review of Palaeobotany and Palynology, v. 71, p. 149-190.

-, 2005, Leaf margin analysis: Taphonomic constraints: Palaios, v. 20, p. 498-505. 
Peppe et al. - Paleoclimate and paleoecology using fossil leaves

$1240-, 2007$, Fossil angiosperm leaves and climate: From Wolfe and Dilcher to Burnham and Wilf:

1241

1242

1243

1244

1245

1246

1247

1248

1249

1250

1251

1252

1253

1254

1255

1256

1257

1258

1259

1260

1261

1262

1263

1264 Advances in angiosperm paleobotany and paleoclimatic reconstruction, v. 258, p. 95108.

Greenwood, D. R., Archibald, S. B., Mathewes, R. W., and Moss, P. T., 2005, Fossil biotas from the Okanagan Highlands, southern British Columbia and northeastern Washington state: Climates and ecosystems across an Eocene landscape: Canadian Journal of Earth Sciences, v. 42, no. 2, p. 167-185.

Greenwood, D. R., Wilf, P., Wing, S., and Christophel, D. C., 2004, Paleotemperature estimation using leaf-margin analysis: Is Australia different?: Palaios, v. 19, p. 129-142.

Greenwood, D. R., and Wing, S. L., 1995, Eocene continental climates and latitudinal temperature gradients: Geology, v. 23, no. 11, p. 1044-1048.

Gregory-Wodzicki, K. M., 2000, Relationship between leaf morphology and climate, Bolivia: Implications for estimating paleoclimate from fossil floras: Paleobiology, v. 26, no. 4, p. 668-688.

Gregory, K., 1994, Palaeoclimate and palaeoelevation of the 35 Ma Florissant flora, Front Range, Colorado: Palaeoclimates, v. 1, p. 23-57.

Gregory, K. M., and McIntosh, W. C., 1996, Paleoclimate and paleoelevation of the Oligocene Pitch-Pinnacle flora, Sawatch Range, Colorado: Geological Society of America Bulletin, v. 108, p. $546-561$.

Grichuk, V., 1969, An attempt to reconstruct certain elements of the climate of the Northern Hemisphere in the Atlantic Period of the Holocene: Golotsen. Izd-vo Nauka, Moscow, p. 41-57.

Grimm, G. W., and Denk, T., 2012, Reliability and resolution of the Coexistence Approach-a revalidation using modern-day data: Review of Palaeobotany and Palynology, v. 172, p. $33-47$. 
Peppe et al. - Paleoclimate and paleoecology using fossil leaves

1265 Grimm, G. W., and Potts, A. J., 2016, Fallacies and fantasies: The theoretical underpinnings of 1266 1267 the Coexistence Approach for palaeoclimate reconstruction: Climate of the Past, v. 12, no. 3, p. 611 .

Hall, J. B., and Swaine, M. D., 1981, Distribution and ecology of vascular plants in a tropical rain forest: Forest vegetation in ghana, The Hague, Junk.

Halloy, S. R. P., and Mark, A. F., 1996, Comparative leaf morphology spectra of plant communities in New Zealand, the Andes and the European Alps: Journal of the Royal Society of New Zealand, v. 26, no. 1, p. 41-78.

Harbert, R. S., and Nixon, K. C., 2015, Climate reconstruction analysis using coexistence likelihood estimation (CRACLE): A method for the estimation of climate using vegetation: American journal of botany, v. 102, no. 8, p. 1277-1289.

Heer, O., 1870, Die Miocene flora und fauna Spitzbergens: Flora Fossilis Artica, v. 1-3, p. 1-98.

-, 1878a, Florae fossilis Sachalinensis: Flora Fossilis Artica, v. 4-5, p. 1-61.

-, 1878b, Fossilen flora Sibiriens und des Amurlandes: Flora Fossilis Artica, v. 4-5, p. 1-58.

-, 1882, Die fossile flora Gronlands, Erster Theil: Flora Fossilis Artica, v. 6, p. 1-147.

Hickey, L. J., 1977, Stratigraphy and paleobotany of the Golden Valley Formation (Early Tertiary) of western North Dakota: GSA Memoir, v. 150, p. 1-183.

Hijmans, R. J., Cameron, S. E., Parra, J. L., Jones, P. G., and Jarvis, A., 2005, Very high resolution interpolated climate surfaces for global land areas: International Journal of Climatology, v. 25, no. 15, p. 1965-1978.

Hinojosa, L. F., Armesto, J. J., and Villagran, C., 2006a, Are Chilean coastal forests prePleistocene relicts? Evidence from foliar physiognomy, palaeoclimate, and phytogeography: Journal of Biogeography, v. 33, p. 331-341.

Hinojosa, L. F., Pesce, O., Yabe, A., Uemura, K., and Nishida, H., 2006b, Physiognomical analysis and paleoclimate of the Ligorio Márquez fossil flora, Ligorio Márquez Formation, 46²5's, Chile: Post Cretaceous floristic changes in southern Patagonia, Chile, p. 45-55. 
1291 Hinojosa, L. F., Pérez, F., Gaxiola, A., and Sandoval, I., 2011, Historical and phylogenetic constraints on the incidence of entire leaf margins: Insights from a new South American model: Global Ecology and Biogeography, v. 20, no. 3, p. 380-390.

1294 Holdridge, L. R., 1967, Life zone ecology, San Jose, Costa Rica, Tropical Science Center. 1295 Huff, P. M., Wilf, P., and Azumah, E. J., 2003, Digital future for paleoclimate estimation from 1296 fossil leaves? Preliminary results: Palaios, v. 18, no. 3, p. 266-274.

1297 Jacobs, B. F., 1999, Estimation of rainfall variables from leaf characters in tropical Africa:

1298 Palaeogeography, Palaeoclimatology, Palaeoecology, v. 145, no. 1-3, p. 231-250.

1299 Jacobs, B. F., 2002, Estimation of low-latitude paleoclimates using fossil angiosperm leaves:

1300 Examples from the Miocene Tugen Hills, kenya: Paleobiology, v. 28, no. 3, p. 399-421.

1301 Jacobs, B. F., and Deino, A. L., 1996, Test of climate-leaf physiognomy regression models, their 1302 application to two Miocene floras from Kenya, and ${ }^{40} \mathrm{Ar} /{ }^{39} \mathrm{Ar}$ dating of the Late Miocene Kapturo site: Palaeogeography, Palaeoclimatology, Palaeoecology, v. 123, no. 1-4, p.

Jacobs, B. F., and Herendeen, P. S., 2004, Eocene dry climate and woodland vegetation in tropical Africa reconstructed from fossil leaves from northern Tanzania: Palaeogeography, Palaeoclimatology, Palaeoecology, v. 213, no. 1-2, p. 115-123.

1308 Jackson, S. T., and Overpeck, J. T., 2000, Responses of plant populations and communities to 1309 environmental changes of the late Quaternary: Paleobiology, v. 26, no. sp4, p. 194-220. Jacques, F. M., Su, T., Spicer, R. A., Xing, Y., Huang, Y., Wang, W., and Zhou, Z., 2011, Leaf physiognomy and climate: Are monsoon systems different?: Global and Planetary Change, v. 76 , no. 1 , p. 56-62.

Jones, C. S., Bakker, F. T., Schlichting, C. D., and Nicotra, A. B., 2009, Leaf shape evolution in the South African genus Pelargonium l'her.(Geraniaceae): Evolution, v. 63, no. 2, p. 479497. 
1316 Jordan, G. J., 1997, Uncertainty in palaeoclimatic reconstructions based on leaf physiognomy: 1317 Australian Journal of Botany, v. 45, no. 3, p. 527-547.

$1318-, 2011$, A critical framework for the assessment of biological palaeoproxies: Predicting past 1319 climate and levels of atmospheric $\mathrm{CO}_{2}$ from fossil leaves: New Phytologist, v. 192, no. 1 , 1320 p. 29-44.

1321 Karst, A. L., and Lechowicz, M. J., 2007, Are correlations among foliar traits in ferns consistent 1322 with those in the seed plants?: New Phytologist, v. 173, no. 2, p. 306-312.

1323 Kelly, A. E., and Goulden, M. L., 2008, Rapid shifts in plant distribution with recent climate 1324 1325 change: Proceedings of the National Academy of Sciences, v. 105, no. 33, p. 1182311826.

Kennedy, E. M., 1998, Cretaceous and Tertiary megafloras from New Zealand and their climate signals [PhD: Open University.

Kennedy, E. M., Arens, N. C., Reichgelt, T., Spicer, R. A., Spicer, T. E., Stranks, L., and Yang, J., 2014, Deriving temperature estimates from Southern Hemisphere leaves: Palaeogeography, Palaeoclimatology, Palaeoecology, v. 412, p. 80-90.

Kennedy, E. M., Spicer, R. A., and Rees, P. M., 2002, Quantitative palaeoclimate estimates from the late Cretaceous and Paleocene leaf floras in the northwest of the South Island, New Zealand: Palaeogeography Palaeoclimatology Palaeoecology, v. 184, p. 321-345.

Kershaw, A., 1997, A bioclimatic analysis of early to middle Miocene Brown Coal floras, Latrobe Valley, south-eastern Australia: Australian Journal of Botany, v. 45, no. 3, p. 373-387.

Kershaw, A., and Nix, H., 1988, Quantitative palaeoclimatic estimates from pollen data using bioclimatic profiles of extant taxa: Journal of Biogeography, p. 589-602.

Khan, M. A., Spicer, R. A., Bera, S., Ghosh, R., Yang, J., Spicer, T. E. V., Guo, S.-x., Su, T., Jacques, F., and Grote, P. J., 2014, Miocene to Pleistocene floras and climate of the eastern Himalayan Siwaliks, and new palaeoelevation estimates for the Namling-Oiyug Basin, Tibet: Global and Planetary Change, v. 113, p. 1-10. 
1342 Kovach, W. L., and Spicer, R., 1996, Canonical correspondence analysis of leaf physiognomy:

$$
\begin{aligned}
& \text { A contribution to the development of a new palaeoclimatological tool: Paleoclimates, v. } \\
& \text { 2, p. } 125-138 \text {. }
\end{aligned}
$$

Kowalski, E. A., 2002, Mean annual temperature estimation based on leaf morphology: A test from tropical South America: Palaeogeography, Palaeoclimatology, Palaeoecology, v. 188, no. 3-4, p. 141-165.

Kowalski, E. A., and Dilcher, D. L., 2003, Warmer paleotemperatures for terrestrial ecosystems: Proceedings of the National Academy of Sciences, USA, v. 100, p. 167-170.

Küchler, A. W., 1964, Potential natural vegetation of the conterminous United States, American Geographical Society New York.

Labandeira, C. C., and Currano, E. D., 2013, The fossil record of plant-insect dynamics: Annual Review of Earth and Planetary Sciences, v. 41, p. 287-311.

Larcher, W., 2003, Physiological plant ecology: ecophysiology and stress physiology of functional groups, Springer Science \& Business Media.

Larcher, W., and Winter, A., 1981, Frost susceptibility of palms: Experimental data and their interpretations: Principes, v. 25, p. 143-152.

Lawing, A. M., Eronen, J. T., Blois, J. L., Graham, C. H., and Polly, P. D., 2016, Community functional trait composition at the continental scale: The effects of non-ecological processes: Ecography, v. 13, p. 001-013.

Lawing, A. M., Head, J. J., and Polly, P. D., 2012, The ecology of morphology: The ecometrics of locomotion and macroenvironment in north american snakes, Paleontology in ecology and conservation, Springer, p. 117-146.

Li, L., McCormack, M. L., Ma, C., Kong, D., Zhang, Q., Chen, X., Zeng, H., Niinemets, Ü., and Guo, D., 2015, Leaf economics and hydraulic traits are decoupled in five species-rich tropical-subtropical forests: Ecology letters, v. 18, no. 9, p. 899-906. 
Peppe et al. - Paleoclimate and paleoecology using fossil leaves

1367

1368

1369

1370

1371

1372

1373

1374

1375

1376

1377

1378

1379

1380

1381

1382

1383

1384

1385

1386

1387

1388

1389

1390

1391

1392

Liang, M.-M., Bruch, A., Collinson, M., Mosbrugger, V., Li, C.-S., Sun, Q.-G., and Hilton, J., 2003, Testing the climatic estimates from different palaeobotanical methods: An example from the middle Miocene Shanwang flora of China: Palaeogeography, Palaeoclimatology, Palaeoecology, v. 198, no. 3-4, p. 279-301.

Lielke, K., Manchester, S., and Meyer, H., 2012, Reconstructing the environment of the northern Rocky Mountains during the Eocene/Oligocene transition: Constraints from the palaeobotany and geology of south-western Montana, USA: Acta Palaeobotanica, v. 52, no. 2, p. 317-358.

Little, S. A., Kembel, S. W., and Wilf, P., 2010, Paleotemperature proxies from leaf fossils reinterpreted in light of evolutionary history: PLoS ONE, v. 5, no. 12, p. e15161.

MacGinitie, H. D., 1953, Fossil plants of the Florissant Beds, Colorado, Carnegie Institution of Washington.

MacLeod, N., and Steart, D., 2015, Automated leaf physiognomic character identification from digital images: Paleobiology, v. 41, no. 4, p. 528-553.

Malhado, A., Malhi, Y., Whittaker, R., Ladle, R., Ter Steege, H., Phillips, O., Butt, N., Aragão, L., Quesada, C., and Araujo-Murakami, A., 2009, Spatial trends in leaf size of Amazonian rainforest trees: Biogeosciences, v. 6, no. 8, p. 1563-1576.

McDonald, P. G., Fonseca, C. R., Overton, J. M., and Westoby, M., 2003, Leaf-size divergence along rainfall and soil-nutrient gradients: Is the method of size reduction common among clades?: Functional Ecology, v. 17, no. 1, p. 50-57.

McElwain, J. C., Montañez, I., White, J. D., Wilson, J. P., and Yiotis, C., 2016, Was atmospheric $\mathrm{CO}_{2}$ capped at $1000 \mathrm{ppm}$ over the past 300 million years?: Palaeogeography, Palaeoclimatology, Palaeoecology, v. 441, p. 653-658.

Merkhofer, L., Wilf, P., Haas, M. T., Kooyman, R. M., Sack, L., Scoffoni, C., and Cúneo, N. R., 2015, Resolving Australian analogs for an Eocene Patagonian paleorainforest using leaf size and floristics: American Journal of Botany, v. 102, no. 7, p. 1160-1173. 
Peppe et al. - Paleoclimate and paleoecology using fossil leaves

1393 Merriam, C. H., 1894, Laws of temperature control of the geographic distribution of terrestrial animals and plants, National Geographic Magazine.

Michaletz, S. T., Weiser, M. D., Zhou, J., Kaspari, M., Helliker, B. R., and Enquist, B. J., 2015, Plant thermoregulation: Energetics, trait-environment interactions, and carbon economics: Trends in Ecology \& Evolution, v. 30, no. 12, p. 714-724.

Michel, L. A., Peppe, D. J., Lutz, J. A., Driese, S. G., Dunsworth, H. M., Harcourt-Smith, W. E., 1399 1400 Horner, W. H., Lehmann, T., Nightingale, S., and McNulty, K. P., 2014, Remnants of an ancient forest provide ecological context for Early Miocene fossil apes: Nature Communications, v. 5, p. 3236.

Miller, I. M., Brandon, M. T., and Hickey, L. J., 2006, Using leaf margin analysis to estimate midCretaceous (Albian) paleolatitude of the Baja BC block: Earth and Planetary Science Letters, v. 245, no. 1-2, p. 95-114.

Mooney, H. A., Björkman, O., and Collatz, G. J., 1978, Photosynthetic acclimation to temperature in the desert shrub, Larrea divaricata I. Carbon dioxide exchange characteristics of intact leaves: Plant Physiology, v. 61, no. 3, p. 406-410.

Monteith, J., and Unsworth, M., 2007, Principles of environmental physics, Academic Press. Mosbrugger, V., and Utescher, T., 1997, The coexistence approach - a method for quantitative reconstructions of tertiary terrestrial palaeoclimate data using plant fossils: Palaeogeography, Palaeoclimatology, Palaeoecology, v. 134, no. 1-4, p. 61-86.

New, M., Lister, D., Hulme, M., and Makin, I., 2002, A high-resolution data set of surface climate over global land areas: Climate research, v. 21, no. 1, p. 1-25.

Parkhurst, D. F., and Loucks, O., 1972, Optimal leaf size in relation to environment: The Journal of Ecology, p. 505-537.

Peppe, D. J., Hickey, L. J., Miller, I. M., and Green, W. A., 2008, A morphotype catalogue, floristic analysis, and stratigraphic description of the Aspen Shale flora (Cretaceous- 
Albian) of southwestern Wyoming: Bulletin of the Peabody Museum of Natural History, v. 49, no. 2, p. $181-208$.

Peppe, D. J., Lemons, C. R., Royer, D. L., Wing, S. L., Wright, I. J., Lusk, C. H., and Rhoden, C. H., 2014, Biomechanical and leaf-climate relationships: A comparison of ferns and seed plants: American Journal of Botany, v. 101, no. 2, p. 338-347.

Peppe, D. J., Royer, D. L., Cariglino, B., Oliver, S. Y., Newman, S., Leight, E., Enikolopov, G., Fernandez-Burgos, M., Herrera, F., Adams, J. M., Correa, E., Currano, E. D., Erickson, J. M., Hinojosa, L. F., Hoganson, J. W., Iglesias, A., Jaramillo, C. A., Johnson, K. R., Jordan, G. J., Kraft, N. J. B., Lovelock, E. C., Lusk, C. H., Niinemets, Ü., Peñuelas, J., Rapson, G., Wing, S. L., and Wright, I. J., 2011, Sensitivity of leaf size and shape to climate: Global patterns and paleoclimatic applications: New Phytologist, v. 190, no. 3, p. 724-739.

Peppe, D. J., Royer, D. L., Wilf, P., and Kowalski, E. A., 2010, Quantification of large uncertainties in fossil leaf paleoaltimetry: Tectonics, v. 29, no. 3, p. TC3015.

Pérez-Pérez, J. M., Esteve-Bruna, D., and Micol, J. L., 2010, QTL analysis of leaf architecture: Journal of Plant Research, v. 123, no. 1, p. 15-23.

Polly, P. D., Eronen, J. T., Fred, M., Dietl, G. P., Mosbrugger, V., Scheidegger, C., Frank, D. C., Damuth, J., Stenseth, N. C., and Fortelius, M., 2011, History matters: Ecometrics and integrative climate change biology: Proceedings of the Royal Society of London B: Biological Sciences, p. rspb20102233.

Polly, P. D., and Sarwar, S., Extinction, extirpation, and exotics: Effects on the correlation between traits and environment at the continental level, in Proceedings Annales Zoologici Fennici2014, Volume 51, BioOne, p. 209-226.

Price, C. A., Wing, S., and Weitz, J. S., 2012, Scaling and structure of dicotyledonous leaf venation networks: Ecology letters, v. 15, no. 2, p. 87-95. 
Peppe et al. - Paleoclimate and paleoecology using fossil leaves

1443 Pross J, Contreras L, Bijl PK, Greenwood DR, Bohaty SM, Schouten S, Bendle JA, Röhl U,

Tauxe L, Raine JI, Huck CE, van de Flierdt T, Jamieson SSR, Stickley CE, van de Schootbrugge B, Escutia C, Brinkhuis H, and IODP Expedition 318 Scientists. 2012. Persistent near-tropical warmth on the Antarctic continent during the early Eocene epoch. Nature, $488: 73-77$, doi: 10.1038/nature 11300

Rakotoarinivo, M., Blach-Overgaard, A., Baker, W. J., Dransfield, J., Moat, J., and Svenning, J.C., 2013, Palaeo-precipitation is a major determinant of palm species richness patterns across Madagascar: a tropical biodiversity hotspot: Proceedings of the Royal Society of London B: Biological Sciences, v. 280, no. 1757, p. 20123048.

Reich, P. B., 2014, The world-wide 'fast-slow'plant economics spectrum: A traits manifesto: Journal of Ecology, v. 102, no. 2, p. 275-301.

Reich, P. B., Ellsworth, D. S., Walters, M. B., Vose, J. M., Gresham, C., Volin, J. C., and Bowman, W. D., 1999, Generality of leaf trait relationships: A test across six biomes: Ecology, v. 80, no. 6, p. 1955-1969.

Reich, P. B., Walters, M. B., and Ellsworth, D. S., 1997, From tropics to tundra: Global convergence in plant functioning: Proceedings of the National Academy of Sciences, v. 94, no. 25 , p. $13730-13734$.

Reichgelt T, Kennedy EM, Mildenhall DC, Conran JG, Greenwood DR, Lee DE. 2013. Quantitative palaeoclimate estimates for Early Miocene southern New Zealand: evidence from Foulden Maar. Palaeogeography, Palaeoclimatology, Palaeoecology, 378: 36 - 44, doi: 10.1016/j.palaeo.2013.03.019

Rodriguez, R. E., Debernardi, J. M., and Palatnik, J. F., 2014, Morphogenesis of simple leaves: regulation of leaf size and shape: Wiley Interdisciplinary Reviews: Developmental Biology, v. 3, no. 1, p. 41-57.

Royer, D. L., 2012a, Climate reconstruction from leaf size and shape: New developments and challenges, in Ivany, L. C., and Huber, B. T., eds., Reconstructing Earth's deep-time 
1469

1470

1471

1472

1473

1474

1475

1476

1477

1478

1479

1480

1481

1482

1483

1484

1485

1486

1487

1488

1489

1490

1491

1492

1493

1494

climate: The state of the art in 2012, Paleontological Society Short Course, Volume 18, The Paleontological Society Papers, p. 195-212.

Royer, D. L., 2012, Leaf shape responds to temperature but not $\mathrm{CO}_{2}$ in Acer rubrum: PloS One, v. 7 , no. 11 , p. e49559.

Royer, D. L., Kooyman, R. M., Little, S. A., and Wilf, P., 2009a, Ecology of leaf teeth: A multisite analysis from an Australian subtropical rainforest: Am. J. Bot., v. 96, no. 4, p. 738750.

Royer, D. L., McElwain, J. C., Adams, J. M., and Wilf, P., 2008, Sensitivity of leaf size and shape to climate within Acer rubrum and Quercus kelloggii: New Phytologist, v. 179, no. 3, p. 808-817.

Royer, D. L., Meyerson, L. A., Robertson, K. M., and Adams, J. M., 2009b, Phenotypic plasticity of leaf shape along a temperature gradient in Acer rubrum: PLoS ONE, v. 4, no. 10, p. e7653.

Royer, D. L., Miller, I. M., Peppe, D. J., and Hickey, L. J., 2010, Leaf economic traits from fossils support a weedy habit for early angiosperms: American Journal of Botany, v. 97, no. 3, p. 438-445.

Royer, D. L., Peppe, D. J., Wheeler, E. A., and Niinemets, U., 2012, Roles of climate and functional traits in controlling toothed vs. untoothed leaf margins: American Journal of Botany, v. 99, no. 5, p. 915-922.

Royer, D. L., Sack, L., Wilf, P., Lusk, C. H., Jordan, G. J., Niinemets, U., Wright, I. J., Westoby, M., Cariglino, B., Coley, P. D., Cutter, A. D., Johnson, K. R., Labandeira, C. C., Moles, A. T., Palmer, M. B., and Valladares, F., 2007, Fossil leaf economics quantified: Calibration, Eocene case study, and implications: Paleobiology, v. 33, p. 574-589.

Royer, D. L., and Wilf, P., 2006, Why do toothed leaves correlate with cold climates? Gas exchange at leaf margins provides new insights into a classic paleotemperature proxy: International Journal of Plant Sciences, v. 167, no. 1, p. 11-18. 
1495 1496 1497 1498 1499 1500 1501 1502 1503 1504 1505 1506 1507 1508 1509 1510

Royer, D. L., Wilf, P., Janesko, D. A., Kowalski, E. A., and Dilcher, D. L., 2005, Correlations of climate and plant ecology to leaf size and shape: Potential proxies for the fossil record: American Journal of Botany, v. 92, no. 7, p. 1141-1151.

Sack, L., and Frole, K., 2006, Leaf structural diversity is related to hydraulic capacity in tropical rain forest trees: Ecology, v. 87, no. 2, p. 483-491.

Sack, L., and Scoffoni, C., 2013, Leaf venation: Structure, function, development, evolution, ecology and applications in the past, present and future: New Phytologist, v. 198, no. 4, p. $983-1000$.

Sack, L., Scoffoni, C., John, G. P., Poorter, H., Mason, C. M., Mendez-Alonzo, R., and Donovan, L. A., 2013, How do leaf veins influence the worldwide leaf economic spectrum? Review and synthesis: Journal of Experimental Botany, v. 64, no. 13, p. 4053-4080.

Sack, L., Scoffoni, C., John, G. P., Poorter, H., Mason, C. M., Mendez-Alonzo, R., and Donovan, L. A., 2014, Leaf mass per area is independent of vein length per area: Avoiding pitfalls when modelling phenotypic integration (reply to ): Journal of Experimental Botany, v. 65, no. 18, p. 5115-5123.

Sack, L., Scoffoni, C., McKown, A. D., Frole, K., Rawls, M., Havran, J. C., Tran, H., and Tran, T., 2012, Developmentally based scaling of leaf venation architecture explains global ecological patterns: Nature Communications, v. 3, p. 837.

Sack, L., Tyree, M. T., and Holbrook, N. M., 2005, Leaf hydraulic architecture correlates with regeneration irradiance in tropical rainforest trees: New Phytologist, v. 167, no. 2, p. 403413.

Salvucci, M. E., and Crafts-Brandner, S. J., 2004, Relationship between the heat tolerance of photosynthesis and the thermal stability of Rubisco activase in plants from contrasting thermal environments: Plant Physiology, v. 134, no. 4, p. 1460-1470. 
Peppe et al. - Paleoclimate and paleoecology using fossil leaves

1520 Schmerler, S. B., Clement, W. L., Beaulieu, J. M., Chatelet, D. S., Sack, L., Donoghue, M. J., 1521

1522

1523

1524

1525

1526

1527

1528

1529

1530

1531

1532

1533

1534

1535

1536

1537

1538

1539

1540

1541 Spicer, R. A., Herman, A. B., and Kennedy, E. M., 2004, Foliar physiognomic record of climatic

1542

1543

1544 Spicer, R. A., Herman, A. B., and Kennedy, E. M., 2005, The sensitivity of CLAMP to taphonomic loss of foliar physiognomic characters: Palaios, v. 20, no. 5, p. 429-438. 
1546 Spicer, R. A., Valdes, P. J., Spicer, T. E. V., Craggs, H. J., Srivastava, G., Mehrotra, R. C., and Yang, J., 2009, New developments in CLAMP: Calibration using global gridded meteorological data: Palaeogeography, Palaeoclimatology, Palaeoecology, v. 283, no. 1-2, p. 91-98.

Spicer, R. A., and Yang, J., 2010, Quantification of uncertainties in fossil leaf paleoaltimetry: Does leaf size matter?: Tectonics, v. 29, p. TC6001.

Steart, D. C., Spicer, R. A., and Bamford, M. K., 2011, Is southern Africa different? An investigation of the relationship between leaf physiognomy and climate in southern African mesic vegetation: Review of Palaeobotany and Palynology, v. 162, no. 4, p. 607620.

Stranks, L., and England, P., 1997, The use of a resemblance function in the measurement of climatic parameters from the physiognomy of woody dicotyledons: Palaeogeography, Palaeoclimatology, Palaeoecology, v. 131, no. 1, p. 15-28.

Su, T., Xing, Y. W., Liu, Y. S., Jacques, F. M. B., Chen, W. Y., Huang, Y. S., and Zhou, Z. K., 2010, Leaf margin analysis: A new equation from humid to mesic forests in China: Palaios, v. 25, p. 234-238.

Svenning, J.-C., and Sandel, B., 2013, Disequilibrium vegetation dynamics under future climate change: American Journal of Botany, v. 100, no. 7, p. 1266-1286.

Teodoridis, V., Mazouch, P., Spicer, R. A., and Uhl, D., 2011, Refining CLAMP — investigations towards improving the Climate Leaf Analysis Multivariate Program: Palaeogeography, Palaeoclimatology, Palaeoecology, v. 299, no. 1, p. 39-48.

ter Braak, C. J. F., 1986, Canonical correspondence analysis: A new eigenvector technique for multivariate direct gradient analysis: Ecology, v. 67, no. 5, p. 1167-1179.

Thompson, R., Anderson, K., Pelltier, R., Strickland, L., Bartlein, P., and Shafer, S. L., 2012, Quantitative estimation of climatic parameters from vegetation data in North America by the mutual climatic range technique: Quaternary Science Reviews, v. 51, p. 18-39. 
Peppe et al. - Paleoclimate and paleoecology using fossil leaves

1572 Traiser, C., Klotz, S., Uhl, D., and Mosbrugger, V., 2005, Environmental signals from leaves-a

1573

1574

1575

1576

1577

1578

1579

1580

1581

1582

1583

1584

1585

1586

1587

1588

1589

1590

1591

1592

1593

1594

1595

1596 physiognomic analysis of European vegetation: New Phytologist, v. 166, no. 2, p. 465484.

Upchurch, G., and Wolfe, J., 1987, Mid-Cretaceous to Early Tertiary vegetation and climate: Evidence from fossil leaves and woods, in Friis, E. M., Chaloner, W., and Crane, P. R., eds., Origins of angiosperms and their biological consequences: Cambridge, Cambridge University Press, p. 75-106.

Utescher, T., Bruch, A. A., Erdei, B., François, L., Ivanov, D., Jacques, F. M. B., Kern, A. K., Liu, Y. S., Mosbrugger, V., and Spicer, R. A., 2014, The coexistence approach—theoretical background and practical considerations of using plant fossils for climate quantification: Palaeogeography, Palaeoclimatology, Palaeoecology, v. 410, p. 58-73.

Vaughan, J., 2015, Investigating the genetic basis of natural leaf shape variation in Arabidopsis thaliana: University of York.

Veloz, S. D., Williams, J. W., Blois, J. L., He, F., Otto-Bliesner, B., and Liu, Z., 2012, No-analog climates and shifting realized niches during the late Quaternary: implications for 21stCentury predictions by species distribution models: Global Change Biology, v. 18, no. 5, p. $1698-1713$.

Vogel, S., 1970, Convective cooling at low airspeeds and the shapes of broad leaves: Journal of Experimental Botany, v. 21, no. 1, p. 91-101.

-, 2009, Leaves in the lowest and highest winds: Temperature, force and shape: New Phytologist, v. 183, no. 1, p. 13-26.

Von Humboldt, A., and Bonpland, A., 1807, Essay on the geography of plants with a physical tableau of the equinoctial regions, in Jackson, S. T., ed., 2009, A. von Humboldt and A. Bonpland, Essay on the geography of plants: Chicago, Illinois, USA, University of Chicago Press, p. 57-143. 
Webb, L. J., 1959, A physiognomic classification of Australian rain forests: Journal of Ecology, v. 47 , no. $551-570$.

-, 1968, Environmental relationships of structural types Australian rain forest vegetation: Ecology, v. 49, no. 2, p. 296-311.

West CK, Greenwood DR, Basinger JF. 2015. Was the Arctic Eocene 'rainforest' monsoonal? Estimates of seasonal precipitation from early Eocene megafloras from Ellesmere Island, Nunavut. Earth \& Planetary Science Letters, 427: 18-30, doi: 10.1016/j.epsl.2015.06.036

Westoby, M., Falster, D. S., Moles, A. T., Vesk, P. A., and Wright, I. J., 2002, Plant ecological 1606 strategies: Some leading dimensions of variation between species: Annual Review of Ecology and Systematics, v. 33, no. 1, p. 125-159.

Whittaker, R. H., 1975, Communities and ecosystems, New York, Macmillan.

Wiemann, M. C., Manchester, S. R., Dilcher, D. L., Hinojosa, L. F., and Wheeler, E. A., 1998, Estimation of temperature and precipitation from morphological characters of dicotyledonous leaves: American Journal of Botany, v. 85, no. 12, p. 1796-1802.

Wilf, P., 1997, When are leaves good thermometers? A new case for leaf margin analysis:

$1614-, 2008$, Fossil angiosperm leaves: Paleobotany's difficult children prove themselves: Paleontological Society Papers, v. 14, p. 319-333.

1616 Wilf, P., Wing, S. L., Greenwood, D. R., and Greenwood, C. L., 1998, Using fossil leaves as paleoprecipitation indicators: An Eocene example: Geology, v. 26, no. 3, p. 203-206.

1618 -, 1999, Using fossil leaves as paleoprecipitation indicators: An Eocene example: Reply:

1619 Geology, v. 27, no. 1, p. 92-92.

1620 Wilf, P., Labandeira, C. C., Johnson, K. R., and Ellis, B. 2006. Decoupled plant and insect 1621 diversity after the end-Cretaceous extinction event: Science, v. 313, no. 5790, p. 11121115, doi: 10.1126/science.1129569. 
1623 Wilf, P., Zhang, S., Chikkerur, S., Little, S. A., Wing, S. L., and Serre, T., 2016, Computer vision 1624 cracks the leaf code: Proceedings of the National Academy of Sciences, p. 201524473.

1625 1626 1627 1628 1629 1630 1631 1632 1633 1634 1635 1636 1637 1638 1639 1640 1641 1642 1643 1644 1645 1646 1647

Wing, S., Bao, H., and Koch, P. L., 2000, An Eocene cool period? Evidence for continental cooling during the warmest part of the Cenozoic, in Huber, B. T., MacCleod, K. G., and Wing, S., eds., Warm climates in Earth history: Cambridge, UK, Cambridge University Press, p. 197-237.

Wing, S., and Greenwood, D. R., 1993, Fossils and fossil climate: The case for equable continental interiors in the Eocene: Philosophical Transactions of the Royal Society of London Series B, v. 341, p. 243-252.

Wing, S. L., Herrera, F., Jaramillo, C. A., Gomez-Navarro, C., Wilf, P., and Labandeira, C. C., 2009, Late Paleocene fossils from the Cerrejon Formation, Colombia, are the earliest record of neotropical rainforest: Proceedings of the National Academy of Sciences, v. 106, no. 44, p. 18627-18632.

Wolfe, J., and Hopkins, D., 1967, Climatic changes recorded by Tertiary land floras in northwestern North America, in Hatai, K., ed., Tertiary correlations and climatic changes in the pacific: Tokyo, Japan, Eleventh Pacific Science Congress, p. 67-76.

Wolfe, J. A., 1971, Tertiary climatic fluctuations and methods of analysis of Tertiary floras: Palaeogeography, Palaeoclimatology, Palaeoecology, v. 9, no. 1, p. 27-57.

Wolfe, J. A., 1978, A paleobotanical interpretation of Tertiary climates in the Northern Hemisphere: Data from fossil plants make it possible to reconstruct Tertiary climatic changes, which may be correlated with changes in the inclination of the Earth's rotational axis: American Scientist, v. 66, no. 6, p. 694-703.

Wolfe, J. A., 1979, Temperature parameters of humid to mesic forests of eastern Asia and relation to forests of other regions in the Northern Hemisphere and Australasia: United States Geological Survey Professional Paper, v. 1106, p. 1-37. 
1648

1649

1650

1651

1652

1653

1654

1655

1656

1657

1658

1659

1660

1661

1662

1663

1664

1665

1666

1667

1668

1669

1670

1671

1672

1673

Wolfe, J. A., 1990, Palaeobotanical evidence for a marked temperature increase following the Cretaceous/Tertiary boundary: Nature, v. 343, no. 6254, p. 153-156.

Wolfe, J. A., 1993, A method of obtaining climatic parameters from leaf assemblages: United States Geological Survey Bulletin, v. 2040, p. 1-71.

-, 1995, Paleoclimatic estimates from Tertiary leaf assemblages: Annual Review of Earth and Planetary Sciences, v. 23, p. 119-142.

Wolfe, J. A., and Spicer, R. A., 1999, Fossil leaf character states; multivariate analyses, in Jones, T. P., and Rowe, N. P., eds., Fossil plants and spores; modern techniques: London, United Kingdon, Geological Society, p. 233-239.

Wolfe, J. A., and Upchurch, G. R., 1987, North American nonmarine climates and vegetation during the Late Cretaceous: Palaeogeography, Palaeoclimatology, Palaeoecology, v. 61, p. 33-77.

Wright, I. J., Reich, P. B., Cornelissen, J. H. C., Falster, D. S., Groom, P. K., Hikosaka, K., Lee, W., Lusk, C. H., Niinemets, Ü., Oleksyn, J., Osada, N., Poorter, H., Warton, D. I., and Westoby, M., 2005, Modulation of leaf economic traits and trait relationships by climate: Global Ecology and Biogeography, v. 14, no. 5, p. 411-421.

Wright, I. J., Reich, P. B., Westoby, M., Ackerly, D. D., Baruch, Z., Bongers, F., CavenderBares, J., Chapin, T., Cornelissen, J. H. C., Diemer, M., Flexas, J., Garnier, E., Groom, P. K., Gulias, J., Hikosaka, K., Lamont, B. B., Lee, T., Lee, W., Lusk, C., Midgley, J. J., Navas, M.-L., Niinemets, U., Oleksyn, J., Osada, N., Poorter, H., Poot, P., Prior, L., Pyankov, V. I., Roumet, C., Thomas, S. C., Tjoelker, M. G., Veneklaas, E. J., and Villar, R., 2004, The worldwide leaf economics spectrum: Nature, v. 428, no. 6985, p. 821-827.

Yang, J., Spicer, R. A., Spicer, T. E., Arens, N. C., Jacques, F., Su, T., Kennedy, E. M., Herman, A. B., Steart, D. C., and Srivastava, G., 2015, Leaf form-climate relationships on the global stage: An ensemble of characters: Global Ecology and Biogeography, v. 24 , no. 10 , p. $1113-1125$. 
Peppe et al. - Paleoclimate and paleoecology using fossil leaves

1674 Yang, J., Spicer, R. A., Spicer, T. E., and Li, C.-S., 2011, 'CLAMP online': A new web-based 1675 palaeoclimate tool and its application to the terrestrial Paleogene and Neogene of North 1676 America: Palaeobiodiversity and Palaeoenvironments, v. 91, no. 3, p. 163-183.

1677 Zagwijn, W., and Hager, H., 1987, Correlations of continental and marine Neogene deposits in 1678 the south-eastern Netherlands and the lower Rhine District: Mededelingen van de 1679 Werkgroep voor Tertiaire en Kwartaire Geologie, v. 24, no. 1-2, p. 59-78. 
A

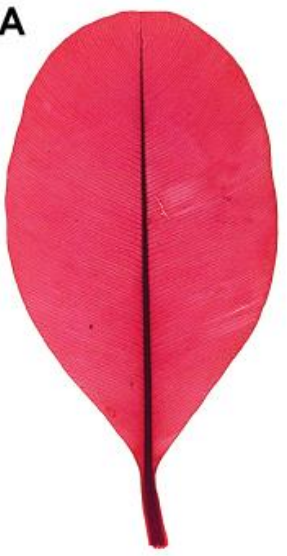

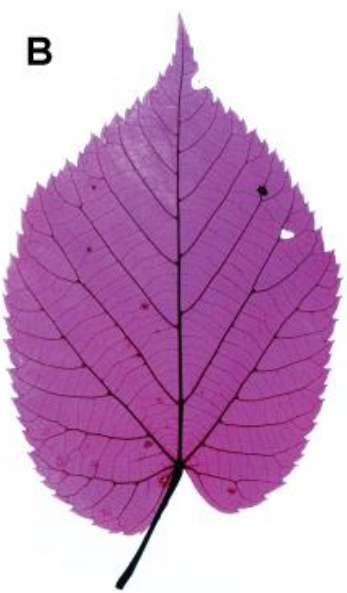
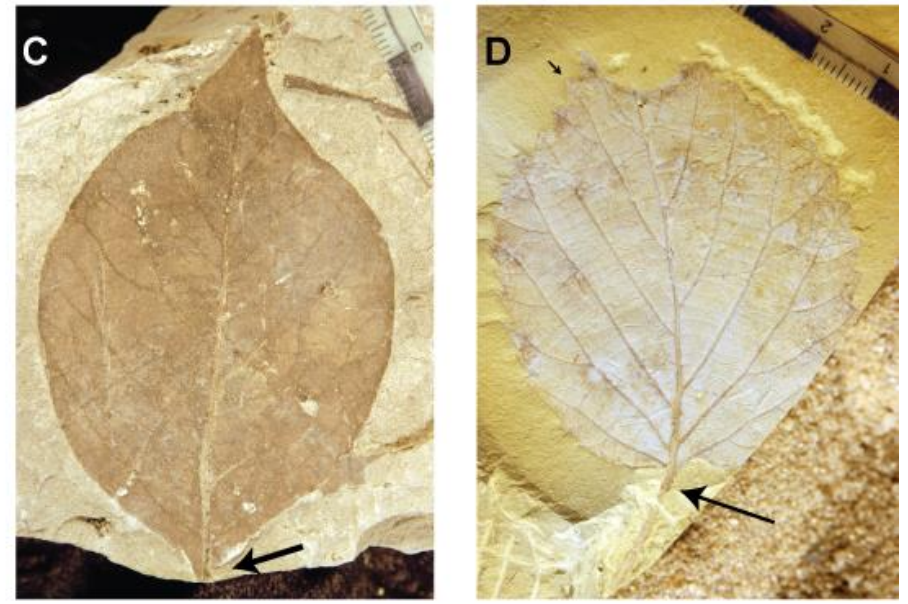

1683

1684 Fig.1. Examples of modern and fossil leaves of woody dicotyledonous angiosperms with entire 1685 (A,C) and toothed (B,D) margins. (A) Cleared and stained leaf of Calophyllujm calabea with an 1686 entire margin (NCLC4372). (B) Cleared and stained leaf of Tilia heterophylla with a toothed 1687 margin (NCLC5403). (C) Unidentified Paleocene fossil leaf from the Fort Union Formation, 1688 Williston Basin, North Dakota, USA with an entire margin (YPM52359). Black arrow indicate 1689 location of petiolar attachment. (D) Davidia antiqua, Paleocene fossil leaf from the Fort Union 1690 Formation, Powder River Basin, Montana, USA with a toothed margin (DMNH28307). Large 1691 black arrow indicates the leaf's petiole. Small black arrow in upper left indicates one of the leaf's 1692 teeth. 

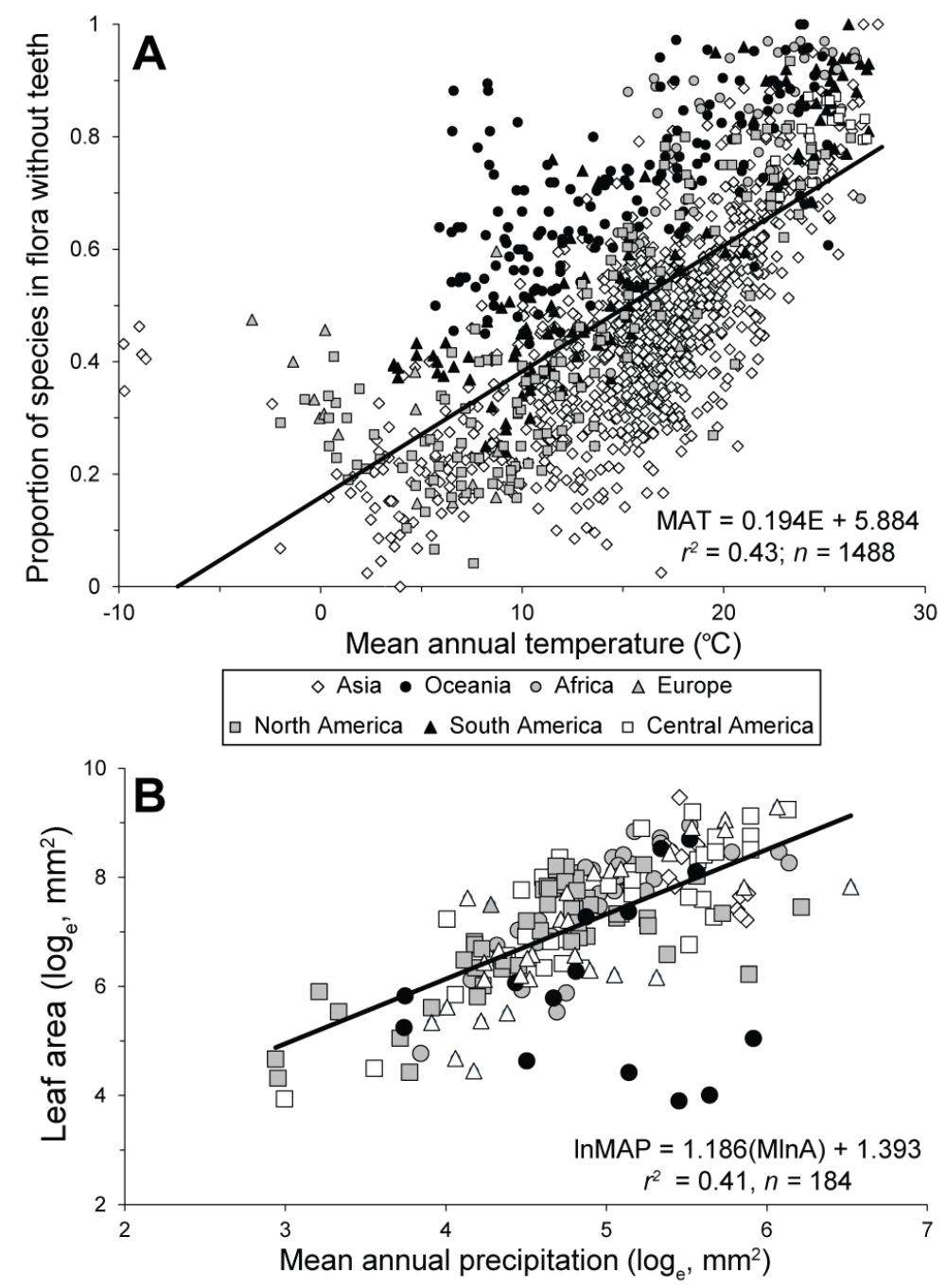

1695

1696 Fig. 2. Univariate leaf physiognomic models for estimating mean annual temperature (MAT) and 1697 mean annual precipitation (MAP). (A) Relationship between the proportion of untoothed species 1698 in a flora and MAT for 1488 globally distributed sites. Linear regression fit shown $\left(r^{2}=0.43, F=\right.$ 1699 1113, $P<0.001)$. Data from Wolfe (1979, 1993), Midgley et al. (1995), Wilf (1997), Kennedy, 1700 (1998), Jacobs, (1999, 2002), Burnham et al. (2001), Greenwood et al. (2004), Royer et al. 1701 (2005), Hinojosa et al. (2006), Aizen and Ezcurra (2008), Su et al. (2010), Peppe et al. (2011), 1702 Chen et al. (2014), Yang et al. (2015). (B) Relationship between mean leaf area and MAP for 1703184 globally distributed sites. Linear regression fit shown $\left(r^{2}=0.41, F=126, P<0.001\right)$. Data 1704 from Wilf et al. (1998), Jacobs (1999, 2002), Gregory-Wodzicki (2000), and Peppe et al. (2011). 


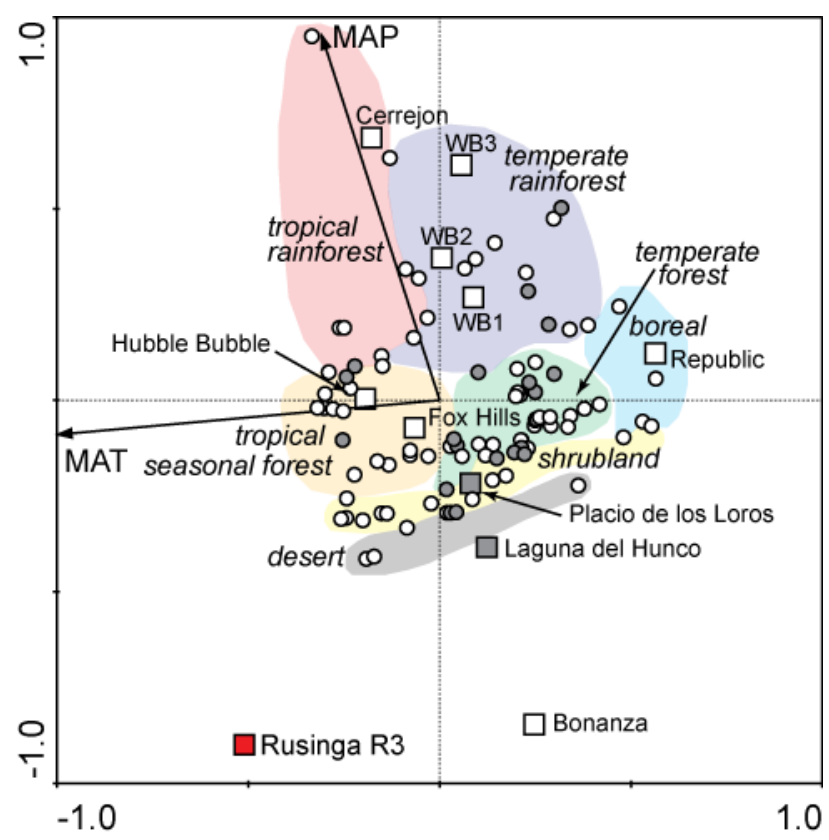

1706 Fig. 3. Canonical correspondence analysis plot of the digital leaf physiognomy (DiLP) calibration

1707 dataset and fossil sites based on leaf physiognomy from Peppe et al. (2011) with modern

1708 biomes mapped onto plot. Extant sites indicated by circles and fossil sites indicated by squares.

1709 Site from the Northern Hemisphere are indicated by white symbols and sites from the Southern

1710 Hemisphere by gray symbols. The Rusinga R3 fossil site, which is indicated by a red square,

1711 falls well outside the leaf physiognomic space of the extant floras in the current DiLP calibration

1712 demonstrating a limitation of the applicability of the method.

1713

1714 


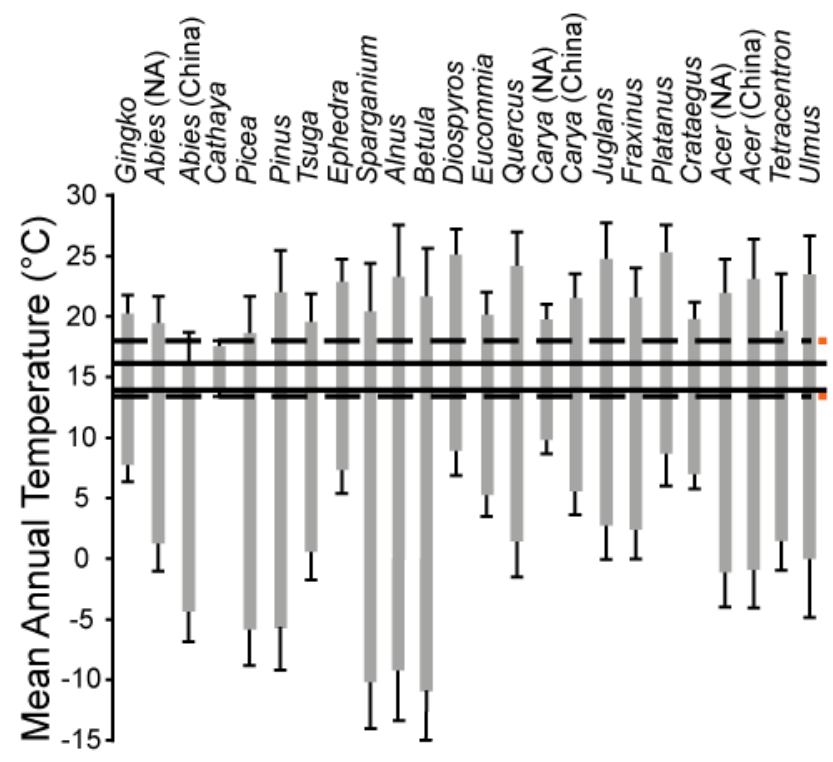

1716 Fig. 4. Coexistence Approach analysis of the latest Eocene Florissant Fossil Beds flora

1717 (Baumgartner and Meyer, 2014). The orange dashed line indicates the estimated coexistence

1718 interval using the full range of climate data, while the solid blue line indicates the estimated

1719 coexistence interval between the $10-90^{\text {th }}$ percentiles. Both coexistence intervals are limited by 1720 Abies and Cathaya; these MAT intervals are estimated as $13.4-18.0^{\circ} \mathrm{C}$ (solid line) and 13.9 -

$172116.2^{\circ} \mathrm{C}$ (dashed line). The age of the flora precludes assigning nearest living relatives at the 1722 species level and some genera (i.e. Betula and Alnus) have relatively large climatic ranges for 1723 MAT. There are no outliers. 
Peppe et al. - Paleoclimate and paleoecology using fossil leaves

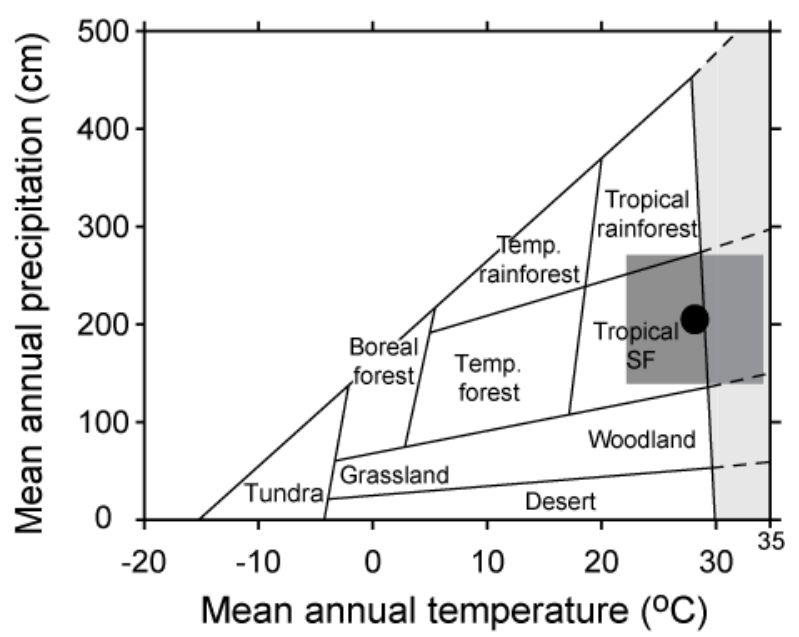

1727 Fig. 5. Climatic reconstruction for the Rusinga R3 fossil site from Michel et al. (2014). Black

1728 circle is the average is of all mean annual temperature and mean annual precipitation estimates.

1729 Shaded square is the range of all climate estimates. Biomes follow Whittaker (1975). Area

1730 shaded in light gray indicates mean annual temperatures higher than recorded today. The

1731 dashed lines represent projections of biomes outside of modern climate space. 


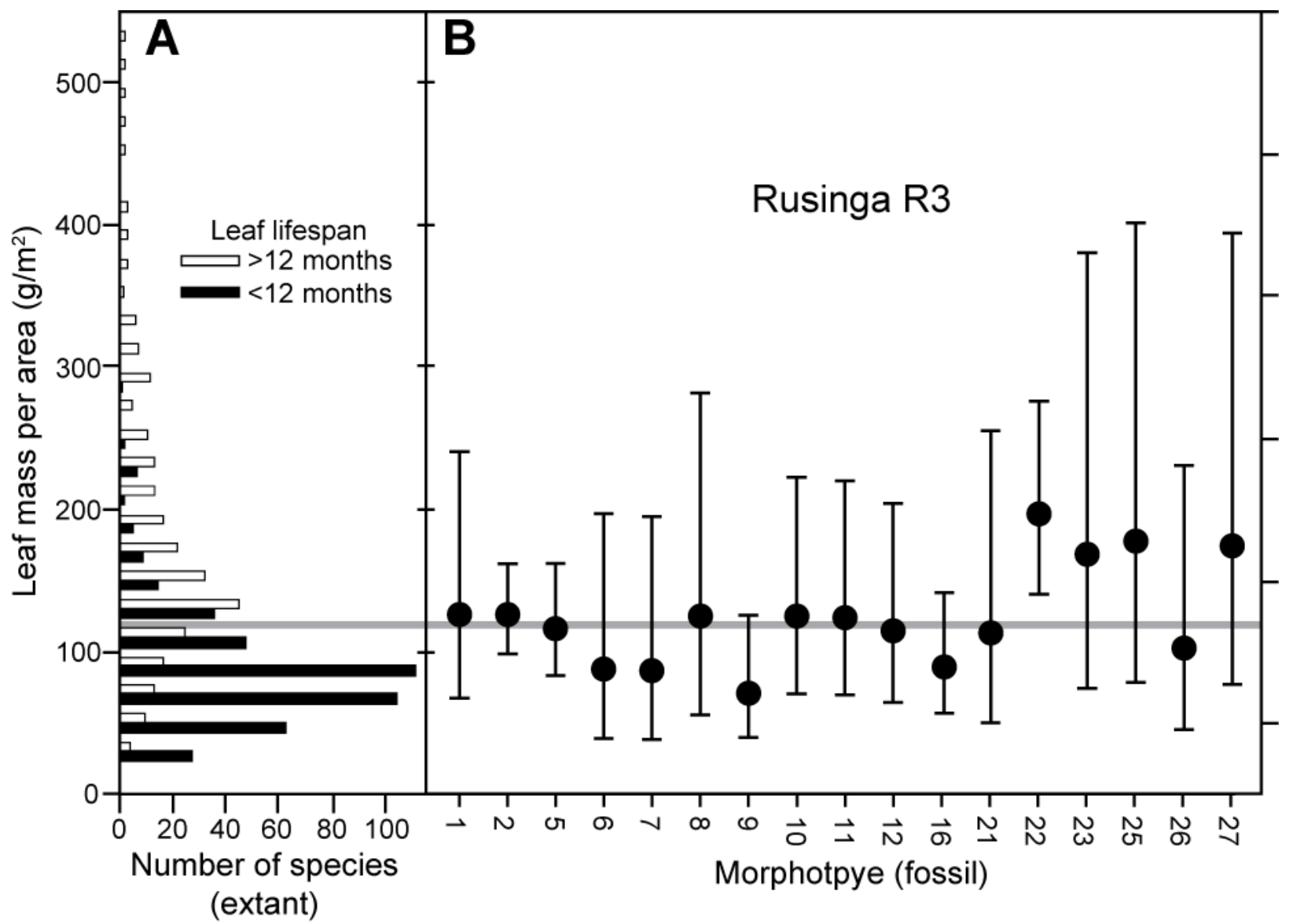

1734 Fig. 6. Estimated leaf mass per area $\left(\mathrm{M}_{2}\right)$ for Rusinga R3 flora and comparison to extant

1735 vegetation. (A) $M_{a}$ and leaf lifespan for 678 species of angiosperms, ferns, and gymnosperms

1736 modified from Royer et al. (2010). $M_{a}$ and leaf lifespan data from Wright et al. (2004). $M_{a}$ bin is

$173720 \mathrm{~g} / \mathrm{m}^{2}$. Gray line at $129 \mathrm{~g} / \mathrm{m}^{2}$ indicates the upper bound of the transition between species

1738 whose leaves are predominately deciduous (leaf life-span $<12$ month) versus those that are

1739 predominately evergreen (leaf lifespan $>12$ months). (B) Estimated $M_{a}$ for 17 morphotypes from

1740 the Rusinga R3 flora showing that the majority of morphotypes were likely evergreen (10 of 17

1741 reconstructed). Errors are $95 \%$ prediction intervals. $M_{a}$ data and morphotypes from Michel et

1742 al. (2014).

1743 


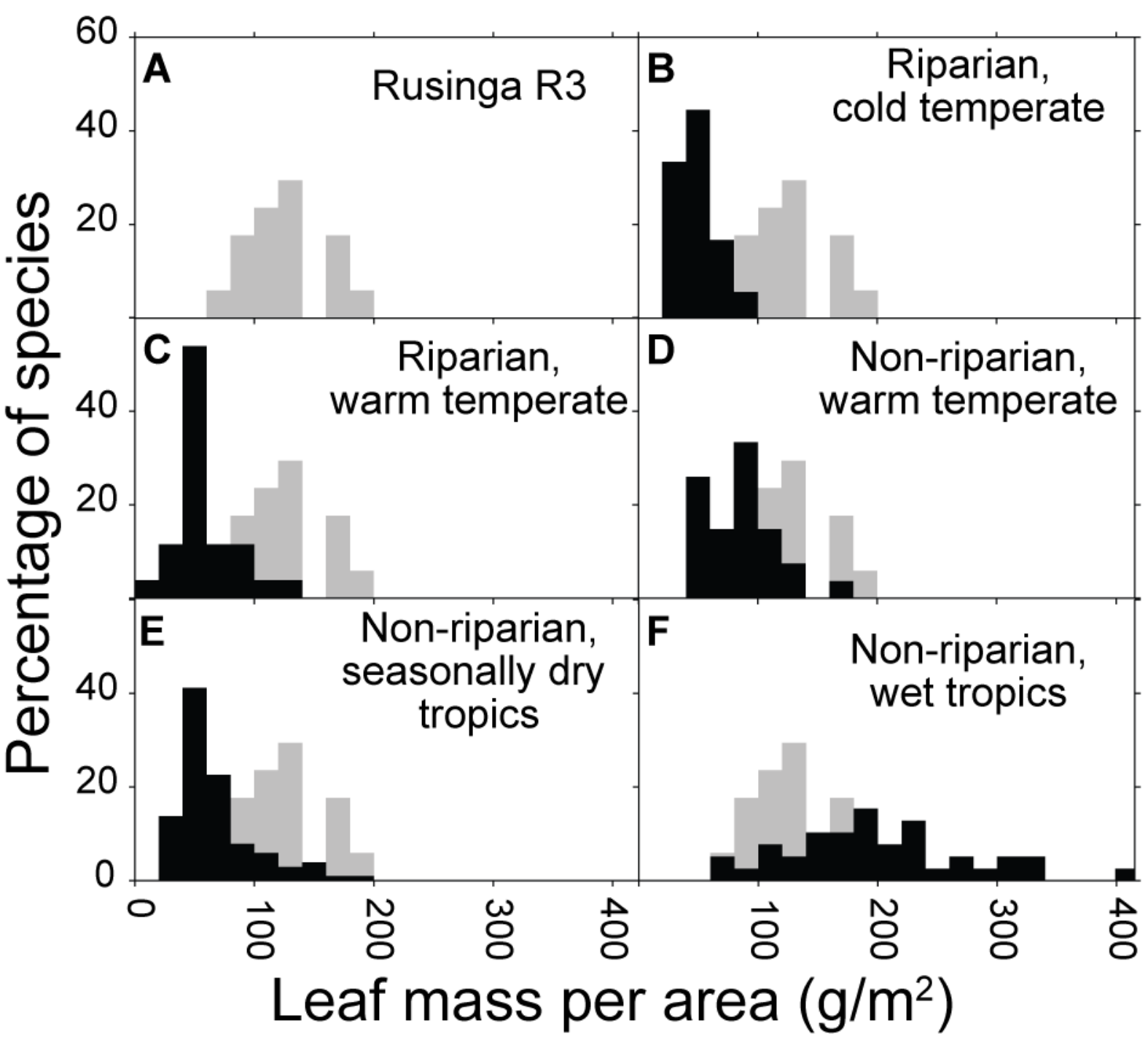

Fig. 7. Comparison of the reconstructed $\mathrm{M}_{\mathrm{a}}$ distribution of the Rusinga R3 flora with extant sites

1746 from varying climate biomes and environments. $M_{a}$ and climate data for extant sites from Peppe

1747 et al. (2011). The fossil and extant sites are comprised of exclusively wood dicot angiosperms.

1748 The $M_{a}$ bin size is $20 \mathrm{~g} / \mathrm{m}^{2}$. (A) Rusinga $R 3$ (replicated in gray in all panels). (B) Connecticut

1749 River, near Middletown, Connecticut, USA. (C) Big Hammock Wildlife Refuge Area, Georgia,

1750 USA. (D) Pee Dee State Park, South Carolina, USA; (E) Barro Colorado Island, Panama. (F)

1751 Buena Vista, Puerto Rico. 
Table 1. Leaf physiognomic models for climate from published literature

\begin{tabular}{|c|c|c|c|c|c|c|c|}
\hline Method & $\begin{array}{l}\text { Reconstructed } \\
\text { climate } \\
\text { variable }\end{array}$ & Equation & Region & $r^{2}$ & $n$ & SE & Authors \\
\hline LMA & MAT & (1) $\mathrm{MAT}=0.306 \mathrm{E}+1.141$ & East Asia & 0.98 & 34 & 0.80 & $\begin{array}{l}\text { (Wolfe, 1979; Wing and } \\
\text { Greenwood, 1993) }\end{array}$ \\
\hline LMA & MAT & (2) $\mathrm{MAT}=0.276 \mathrm{E}+1.038$ & China & 0.79 & 50 & 1.90 & (Su et al., 2010) \\
\hline LMA & MAT & (3) $\mathrm{MAT}=0.223 \mathrm{E}+6.68$ & China & 0.53 & 732 & 3.10 & (Chen et al., 2014) \\
\hline LMA & MAT & (4) MAT $=0.2338 \mathrm{E}+4.6321$ & Japan & 0.74 & 35 & 1.87 & (Kennedy et al., 2014) \\
\hline LMA & MAT & (5) $\mathrm{MAT}=0.314 \mathrm{E}+0.512$ & Europe & 0.60 & 1835 & 1.70 & (Traiser et al., 2005) \\
\hline LMA & MAT & (6) $\mathrm{MAT}=0.291 \mathrm{E}-0.266$ & North, Central America and Japan & 0.76 & 106 & 3.40 & (Wilf, 1997) \\
\hline LMA & MAT & (7) $\mathrm{MAT}=0.286 \mathrm{E}+2.240$ & North, Central and South America & 0.94 & 9 & 2.00 & (Wilf, 1997) \\
\hline LMA & MAT & (8) $\mathrm{MAT}=0.363 \mathrm{E}+2.233$ & North America & 0.80 & 10 & 3.60 & (Kowalski and Dilcher, 2003) \\
\hline LMA & MAT & (9) $\mathrm{MAT}=0.290 \mathrm{E}+1.320$ & North, Central America & 0.91 & 84 & - & (Miller et al., 2006) \\
\hline LMA & MAT & (10) $\mathrm{MAT}=0.2471 \mathrm{E}+2.3305$ & North America & 0.79 & 104 & 2.63 & (Kennedy et al., 2014) \\
\hline LMA & MAT & (11) $\mathrm{MAT}=0.250 \mathrm{E}+3.42$ & Temperate Northern Hemisphere & 0.87 & 144 & 2.20 & (Wolfe, 1993) \\
\hline LMA & MAT & (12) $\mathrm{MAT}=0.275 \mathrm{E}+1.36$ & Temperate Northern Hemisphere & 0.77 & 173 & 3.30 & (Gregory-Wodzicki, 2000) \\
\hline LMA & MAT & (13) $\mathrm{MAT}=0.249 \mathrm{E}+3.53$ & $\begin{array}{l}\text { Temperate Northern Hemisphere } \\
\text { (alpine excluded) }\end{array}$ & 0.87 & 144 & 2.20 & (Gregory-Wodzicki, 2000) \\
\hline LMA & MAT & (14) MAT $=0.2475 E+2.9066$ & Northern Hemisphere & 0.81 & 149 & 2.55 & (Kennedy et al., 2014) \\
\hline LMA & MAT & (15) $\mathrm{MAT}=0.759 \mathrm{E}-0.013$ & $\begin{array}{l}\text { New Zealand, the Andes, the } \\
\text { Alps }\end{array}$ & 0.57 & 19 & - & (Halloy and Mark, 1996) \\
\hline LMA & MAT & (16) $\mathrm{MAT}=0.316 \mathrm{E}-0.059$ & South America & 0.89 & 14 & 1.60 & (Gregory-Wodzicki, 2000) \\
\hline LMA & MAT & (17) MAT $=0.385 E-10.24$ & Tropical South America & 0.47 & 30 & 3.40 & (Kowalski, 2002) \\
\hline LMA & MAT & (18) $\mathrm{MAT}=0.3825 \mathrm{E}-10.9$ & South America (isotherm) & 0.73 & 16 & - & (Aizen and Ezcurra, 2008) \\
\hline LMA & MAT & (19) $\mathrm{MAT}=0.4236 \mathrm{E}-11.37$ & South America (cell) & 0.54 & 16 & - & (Aizen and Ezcurra, 2008) \\
\hline LMA & MAT & (20) $\mathrm{MAT}=0.2603 \mathrm{E}+1.31$ & South America & 0.82 & 51 & 2.80 & (Hinojosa et al., 2011) \\
\hline
\end{tabular}


Peppe et al. - Paleoclimate and paleoecology using fossil leaves

\begin{tabular}{|c|c|c|c|c|c|c|c|}
\hline LMA & MAT & (21) MAT $=0.4396 \mathrm{E}-8.3637$ & South America & 0.93 & 14 & 1.73 & (Kennedy et al., 2014) \\
\hline LMA & MAT & (22) $\mathrm{MAT}=0.2399 \mathrm{E}+3.6916$ & Southern Africa & 0.86 & 25 & - & (Steart et al., 2010) \\
\hline LMA & MAT & (23) $\mathrm{MAT}=0.1094 \mathrm{E}+9.5173$ & Southern Africa & 0.37 & 14 & 2.30 & (Kennedy et al., 2014) \\
\hline LMA & MAT & (24) $\mathrm{MAT}=0.270 \mathrm{E}-2.120$ & Australia & 0.63 & 74 & - & (Greenwood et al, 2004) \\
\hline LMA & MAT & (25) $\mathrm{MAT}=0.0862 \mathrm{E}+17.6547$ & Pacific Islands & 0.35 & 6 & 1.33 & (Kennedy et al., 2014) \\
\hline LMA & MAT & (26) $\mathrm{MAT}=0.0571 \mathrm{E}+16.4785$ & Australia & 0.06 & 21 & 2.34 & (Kennedy et al., 2014) \\
\hline LMA & MAT & (27) MAT $=0.0239 \mathrm{E}+10.561$ & New Zealand & 0.02 & 35 & 1.69 & (Kennedy et al., 2014) \\
\hline LMA & MAT & (28) MAT $=0.257 \mathrm{E}-1.8412$ & Southern Hemisphere & 0.40 & 90 & 4.83 & (Kennedy et al., 2014) \\
\hline LMA & MAT & (29) $\mathrm{MAT}=0.204 \mathrm{E}+4.600$ & $\begin{array}{l}\text { North and South America, Japan, } \\
\text { and Oceania }\end{array}$ & 0.58 & 92 & 4.80 & (Peppe et al., 2011) \\
\hline LMA & MAT & (30) $\mathrm{MAT}=0.2039 \mathrm{E}+3.6562$ & $\begin{array}{l}\text { Oceania, Japan, North America, } \\
\text { South America, Southern Africa }\end{array}$ & 0.57 & 239 & 3.97 & (Kennedy et al., 2014) \\
\hline LMA & MAT & (31) $\mathrm{MAT}=0.194 \mathrm{E}+5.884$ & Global & 0.42 & 1488 & 4.54 & this study \\
\hline LAA & MAT & MAT $=0.115 \mathrm{~A}+1.192$ & $\begin{array}{l}\text { New Zealand, the Andes, the } \\
\text { Alps }\end{array}$ & 0.87 & 19 & - & (Halloy and Mark, 1996) \\
\hline DiLP & MAT & $\begin{array}{l}\mathrm{MAT}=0.210 \mathrm{E}+42.296 \mathrm{D}-2.609 \mathrm{I}- \\
16.004\end{array}$ & $\begin{array}{l}\text { North and South America, Japan, } \\
\text { and Oceania }\end{array}$ & 0.70 & 92 & 4.00 & (Peppe et al., 2011) \\
\hline MLR & MAP & $\begin{array}{l}\text { (1) MAP }=167.948(\text { apex attenuate) } \\
+377.735 \text { (mesophyll2) }+11.489\end{array}$ & Temperate Northern Hemisphere & 0.50 & 74 & 57.96 & (Wing and Greenwood, 1993) \\
\hline $\begin{array}{l}\text { hodified } \\
\text { LAA }\end{array}$ & MAP & $\begin{array}{l}\text { (2) MAP }=6.18 \text { (mesophyll1 }+ \\
\text { mesophyll2) }+47.5\end{array}$ & Temperate Northern Hemisphere & 0.44 & 74 & - & (Wilf et al., 1998) \\
\hline LAA & MAP & (3) $\operatorname{lnMAP}=0.484(M n A)+1.78$ & Temperate Northern Hemisphere & 0.61 & 144 & 0.47 & (Gregory-Wodzicki, 2000) \\
\hline LAA & MAP & $(4) \operatorname{lnMAP}=0.548(M n A)+0.786$ & $\begin{array}{l}\text { North, Central and South } \\
\text { America, Africa }\end{array}$ & $\begin{array}{c}50.0 \\
0\end{array}$ & 50 & 0.36 & (Wilf et al., 1998) \\
\hline LAA & MAP & (5) $\operatorname{lnMAP}=0.298(M n A)+2.64$ & Bolivia & 0.52 & 12 & 0.22 & (Gregory-Wodzicki, 2000) \\
\hline LAA & MAP & $\begin{array}{l}(6) \operatorname{InMAP}=1.369(\text { mesophyll1 }+ \\
\text { mesophyll2) }+3.982\end{array}$ & Africa and Bolivia & 0.83 & 42 & 0.18 & (Jacobs, 2002) \\
\hline LAA & MAP & $(7) \operatorname{lnMAP}=0.309(\mathrm{Mn} A)+2.566$ & Tropical Africa and Bolivia & 0.73 & 42 & - & $\begin{array}{l}\text { (Jacobs and Heredeen, } \\
\text { 2004) }\end{array}$ \\
\hline MLR & MAP & $\begin{array}{l}\text { (8) InMAP }=0.6903(\text { mesophyll })+ \\
0.7059(\text { apex acuminate })+ \\
0.884(\text { apex acute })+0.7542 E+ \\
4.9415\end{array}$ & Africa & 0.79 & 30 & 0.19 & (Jacobs, 1999) \\
\hline
\end{tabular}


Peppe et al. - Paleoclimate and paleoecology using fossil leaves

\begin{tabular}{|c|c|c|c|c|c|c|c|}
\hline MLR & MAP & $\begin{array}{l}(9) \text { InMAP }=1.274 \text { (mesophyll } 1+ \\
\text { mesophyll2) - } 1.013 \text { (shape elliptic) }+ \\
5.198\end{array}$ & Africa & 0.81 & 30 & 0.18 & (Jacobs, 2002) \\
\hline $\begin{array}{l}\text { modified } \\
\text { LAA }\end{array}$ & MAP & $\begin{array}{l}(10) \text { InMAP }=1.321(\text { mesophyll1 + } \\
\text { mesophyll2) }+4.018\end{array}$ & Africa & 0.76 & 30 & 0.20 & (Jacobs, 2002) \\
\hline LAA & MAP & $(11) \ln M A P=0.321(M n A)+2.476$ & Africa & 0.66 & 30 & 0.24 & (Jacobs, 2002) \\
\hline LAA & MAP & $\begin{array}{l}(12) \operatorname{lnMAP}(<260 \mathrm{~cm})= \\
0.354(\mathrm{Mn} A)+2.167\end{array}$ & $\begin{array}{l}\text { Tropical Africa, Bolivia, tropical to } \\
\text { subtropical Western Hemisphere }\end{array}$ & 0.71 & 79 & - & (Jacobs, 2002) \\
\hline LAA & MAP & $(13) \operatorname{InMAP}=0.429(M n A)+1.705$ & $\begin{array}{l}\text { Western Hemisphere, Bolivia, } \\
\text { Africa }\end{array}$ & 0.71 & 92 & 0.34 & (Jacobs, 2002) \\
\hline LAA & MAP & (14) $\mathrm{MAP}=0.001 \mathrm{~A}+0.551$ & $\begin{array}{l}\text { New Zealand, the Andes, the } \\
\text { Alps }\end{array}$ & 0.71 & 19 & - & (Halloy and Mark, 1996) \\
\hline LAA & MAP & $(15) \ln M A P=0.283(M \ln A)+2.92$ & $\begin{array}{l}\text { North and South America, Japan, } \\
\text { and Oceania }\end{array}$ & 0.23 & 92 & 0.61 & (Peppe et al., 2011) \\
\hline LAA & MAP & $(16) \ln M A P=0.346(M \ln A)+2.404$ & global & 0.41 & 184 & 0.93 & this study \\
\hline DiLP & MAP & $\begin{array}{l}\operatorname{lnMAP}=0.298(\mathrm{Mln} A)-2.717(\operatorname{InP})+ \\
0.279(\operatorname{Inl})-3.033\end{array}$ & $\begin{array}{l}\text { North and South America, Japan, } \\
\text { and Oceania }\end{array}$ & 0.27 & 92 & 0.60 & (Peppe et al., 2011) \\
\hline MLR & GSP & $\begin{array}{l}\text { (1) GSP }(<222 \mathrm{~cm})=141.368 \\
\text { (mesophyll2) }-136.340(\mathrm{~L}: \mathrm{W}<1)+ \\
93.936(\text { shape elliptic) }-79.774(\text { base } \\
\text { round) }-52.386 \text { (teeth acute })+ \\
48.050\end{array}$ & Temperate Northern Hemisphere & 0.80 & 74 & 16.00 & $\begin{array}{l}\text { (Gregory and Mclntosh, } \\
\text { 1996) }\end{array}$ \\
\hline MLR & GSP & $\begin{array}{l}\text { (2) GSP }=-3.393 \text { (leptophyll2) } \\
+2.40 \text { (apex attenuate) }-2.671 \text { (base } \\
\text { cordate) }+2.360(\text { L:W 2-3) }+3.122 \\
(\text { L:W 3-4:1) }+31.6\end{array}$ & $\begin{array}{l}\text { Temperate Northern Hemisphere } \\
\text { (alpine excluded) }\end{array}$ & 0.80 & 144 & - & (Wiemann et al., 1998) \\
\hline MLR & GSP & $\begin{array}{l}\text { (3) GSP }(<222 \mathrm{~cm})=1.60(\text { apex } \\
\text { attenuate })+2.80(\mathrm{~L}: \mathrm{W} 2-3)-45.2\end{array}$ & $\begin{array}{l}\text { Temperature Northern } \\
\text { Hemisphere (alpine excluded) }\end{array}$ & 0.63 & 144 & 27.00 & (Gregory-Wodzicki, 2000) \\
\hline MLR & $\begin{array}{l}\text { Wet months } \\
\text { precipitation }\end{array}$ & $\begin{array}{l}\text { (1) In Wet Ppn }=0.8368 \text { (mesophyll) } \\
+0.819 \text { (apex acuminate) }+ \\
1.1718 \text { (apex acute) }+0.8246 \text { (no } \\
\text { teeth) }+4.4993\end{array}$ & Africa & 0.80 & 30 & 0.22 & (Jacobs, 1999) \\
\hline $\begin{array}{l}\text { modified } \\
\text { LAA }\end{array}$ & $\begin{array}{l}\text { Wet months } \\
\text { precipitation }\end{array}$ & $\begin{array}{l}\text { (2) In Wet Ppn }=1.546(\text { mesophyll1 } \\
+ \text { mesophyll2) }+6.112\end{array}$ & Africa & 0.78 & 30 & 0.22 & (Jacobs, 2002) \\
\hline $\begin{array}{l}\text { modified } \\
\text { LAA }\end{array}$ & $\begin{array}{l}\text { Wet months } \\
\text { precipitation }\end{array}$ & $\begin{array}{l}\text { (3) In Wet Ppn }=1.601 \text { (mesophyll1 } \\
+ \text { mesophyll2) }+3.777\end{array}$ & Africa and Bolivia & 0.83 & 42 & 0.21 & (Jacobs, 2002) \\
\hline
\end{tabular}


Peppe et al. - Paleoclimate and paleoecology using fossil leaves

\begin{tabular}{|c|c|c|c|c|c|c|c|}
\hline $\begin{array}{l}\text { modified } \\
\text { LAA }\end{array}$ & $\begin{array}{l}\text { Wet months } \\
\text { precipitation }\end{array}$ & (4) In Wet Ppn $=0.367(M n A)+2.07$ & Tropical Africa and Bolivia & 0.75 & 42 & - & $\begin{array}{l}\text { (Jacobs and Heredeen, } \\
\text { 2004) }\end{array}$ \\
\hline MLR & $\begin{array}{l}\text { Wet months } \\
\text { precipitation }\end{array}$ & $\begin{array}{l}\text { 3-WET }=110.841 \text { (apex attenuate) }+ \\
320.457(\text { L:W 2-3:1) + } \\
179.775 \text { (mesophyll2) - } 172.859\end{array}$ & Temperate Northern Hemisphere & 0.58 & 74 & 47.23 & (Wing and Greenwood, 1993) \\
\hline MLR & $\begin{array}{l}\text { Dry months } \\
\text { precipitation }\end{array}$ & $\begin{array}{l}\text { 3-DRY = 45.54(apex attenuate })+ \\
\text { 38.186(L:W 2-3:1) - 24.489 }\end{array}$ & $\begin{array}{l}\text { Temperature Northern } \\
\text { Hemisphere }\end{array}$ & 0.55 & 74 & 8.91 & (Wing and Greenwood, 1993) \\
\hline
\end{tabular}

LMA = leaf margin analysis, $L A A=$ leaf area analysis, $M L R=$ multiple linear regression model, DiLP $=$ digital leaf physiognomy, MAT $=$ mean annual temperature, $\mathrm{MAP}=$ mean annual precipitation, GSP = growing season precipitation, wet months precipitation = precipitation during the three wettest months of the year, dry monts precipitation $=$ precipitation during the three driest months of the year, $\mathrm{E}=$ percent of woody dicots with entire margins, $\mathrm{A}=$ leaf area, $\mathrm{D}=\mathrm{Feret} \mathrm{s}$ diameter ratio, I = number of teeth: internal perimeter, $\mathrm{P}=$ perimeter ratio, $M n A=$ average leaf area of all dicot species 
Peppe et al. - Paleoclimate and paleoecology using fossil leaves

Table 2. Leaf mass per are models for woody dicot angiosperms, herbaceous angiosperms, broadleaf gymnosperms, and ferns

Taxonomic Group

\section{Model}

a

woody dicot angiosperms

herbaceous angiosperms

broadleaf gymnosperms

ferns

$\log \left(M_{A}\right)=a+b \log \left(P W^{2} / A\right)$

$\log \left(M_{A}\right)=a+\operatorname{blog}\left(P W^{2} / A\right)$

$\log \left(M_{A}\right)=a+b \log \left(P W^{2} / A\right)$

$\log \left(M_{A}\right)=a+b \log \left(P W^{4} / A\right)$

Royer et al.

Authors

3.07

0.382

(2007)

3.015

0.3076

Royer et al.

2.245

0.2204

(2010)

4.207

0.252

Royer et al.

0.32 (2010)

Peppe et al. $0.44 \quad(2014)$ 